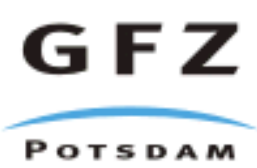

Originally published as:

Milsch, H., Blöcher, G., Engelmann, S. (2008): The relationship between hydraulic and electrical transport properties in sandstones: An experimental evaluation of several scaling models. - Earth and Planetary Science Letters, 275, 3-4, 355-363

DOI: 10.1016/j.epsl.2008.08.031 


\title{
The relationship between hydraulic and electrical transport properties in sandstones: An experimental evaluation of several scaling models.
}

\author{
Harald Milsch $^{1}$, Guido Blöcher ${ }^{1}$, and Silvio Engelmann ${ }^{1,2}$ \\ ${ }^{1}$ Deutsches GeoForschungsZentrum, Telegrafenberg, D-14473 Potsdam, Germany, \\ milsch@gfz-potsdam.de \\ ${ }^{2}$ Technische Universität Berlin, Institut für Angewandte Geowissenschaften, Ackerstr. 76, \\ D-13355 Berlin, Germany
}

\begin{abstract}
The purpose of this paper is to investigate the relationship between the parameters that define the hydraulic and electrical transport in porous rock. We therefore measured the effective pressure dependence of both permeability $(k)$ and (specific) electrical conductivity $(\sigma)$ of three different types of sandstones (Fontainebleau, Flechtinger, and Eberswalder). The experiments were performed in a high pressure and high temperature (HPT) permeameter at a maximum confining- and pore pressure of $50 \mathrm{MPa}$ and $45 \mathrm{MPa}$, respectively and a constant temperature of $40^{\circ} \mathrm{C}$. 0.1 molar NaCl-brine was used as the pore fluid. We show that for the present rockfluid combinations surface conductivity can be neglected. The experiments were complemented with 2D image analysis and mercury porosimetry to derive the average pore radii, the specific inner pore surfaces, and the pore radius distributions of the samples. The experimental and microstructural results were used to relate both transport properties by means of different length scales and to test the associated scaling models based on (1) the equivalent channel concept, (2) statistics and percolation, and (3) an interpretation of mercury porosimetry data. As the principal result, none of these integrated models could adequately reproduce the respective transport property within experimental error margins. Furthermore, it is emphasized that these models are not applicable for effective pressures other than zero unless the concurrent evolution of the microstructure, respectively the length scale, can be characterized. By comparison, it is shown that purely empirical permeability-conductivity relationships can always be adjusted to provide a reasonable description of the coupled $k-\sigma$ dependence on effective pressure. However, it is implied that the included empirical length parameter is fundamentally different from the ones above as it is a pressure independent constant that contains no true microstructural or physical information.
\end{abstract}

\section{Key Words}

permeability, electrical conductivity, transport properties, petrophysics, scaling models, sandstone 


\section{Introduction}

Both permeability $(k)$ and (specific) electrical conductivity $(\sigma)$ are important rock transport properties whose determination is of uppermost interest in all areas where the characterization of fluid flow within a pore space is the key issue. For example, forecasts on the productivity of hydrocarbon and geothermal reservoirs require a reliable estimate of the permeability of the constituent rocks. Both parameters are measured as bulk properties but are in fact defined by the individual pore structure of a rock. This is evident for permeability but is also true for the electrical conductivity as long as the latter is governed by the conductivity of a fluid within the pore space, in other words, as long as surface conductivity can be neglected. Furthermore, the pore structure is affected by changes in the state of stress acting on the rock. Both transport properties are therefore dependent on effective stress or, in the lithostatic (isotropic) case, on effective pressure $\left(p_{\text {eff }}\right)$. In the present study the term "effective pressure" is defined as the difference between confining- $\left(p_{c}\right)$ and pore pressure $\left(p_{p}\right)$ according to Terzaghi's Principle ( $p_{\text {eff }}=p_{c}-p_{p}$; Terzaghi, 1923). It is thus synonymously used with the term "differential pressure". Compared to permeability, electrical rock conductivity is significantly easier to measure both in the lab and in situ. Thus, not least for practical reasons, it is desirable to establish a link between both transport properties and to couple both parameters through microstructure-related length scales.

Such approaches have been made repeatedly during the last five decades (e.g. Wyllie and Rose, 1950; Walsh and Brace, 1984; Johnson et al., 1986; Katz and Thompson, 1986, 1987; Guéguen and Dienes, 1989; Avellaneda and Torquato, 1991; Martys and Garboczi, 1992). The strategy applied in these models is, first, to set up independent expressions for both hydraulic and electrical transport as a function of the pore space microstructure. The rock permeability $(k)$ and the specific electrical rock conductivity $(\sigma)$ are defined by the Darcy Equation (Eq. 1; Darcy, 1856) and Ohm's Law (Eq. 2; Ohm, 1826), respectively: 


$$
\boldsymbol{q}=-\frac{k}{\eta} \nabla \boldsymbol{p}
$$

$$
\boldsymbol{J}=-\sigma \nabla \boldsymbol{V}
$$

where $\boldsymbol{q}, \eta, \nabla \boldsymbol{p}, \boldsymbol{J}$, and $\nabla \boldsymbol{V}$ denote the fluid volume flux, the dynamic fluid viscosity, the pressure gradient, the current flux density, and the potential gradient, respectively. These equations are then related to the microstructural information by means of geometrical (equivalent channel) models (Wyllie and Rose, 1950; Paterson, 1983; Walsh and Brace, 1984) as well as statistical and percolation concepts (Katz and Thompson, 1986, 1987; Guéguen and Dienes, 1989). The two independent expressions are finally joined together to yield a relationship (Eq. 3) that links both transport properties, where the electrical conductivity is expressed in terms of the formation factor $(F)$ :

$$
k=c L^{2} \frac{1}{F},
$$

where $c$ and $L$ denote a shape factor and a characteristic length scale, respectively. The formation factor $F$ here is defined as the ratio between the electrical conductivity of the fluid $\left(\sigma_{f l}\right)$ at the respective experimental temperature and the measured conductivity of the rock $(\sigma)$. The related assumption that, in the present study, surface conductivity can be neglected with respect to the brine conductivity is reasonable as outlined in Section 2.2. In other approaches Eq. 3 is introduced in an ad hoc manner and $L$ is derived by physical considerations like Joule dissipation and electrically weighted pore surface-tovolume ratios (Johnson et al., 1986) or nuclear magnetic resonance (NMR) relaxation times (Avellaneda and Torquato, 1991). 
The physical meaning of both parameters $c$ and $L$ is therefore dependent on the

respective model and can vary significantly. It is thus crucial for the validity of a model that the characteristic length scale $L$ is appropriately defined and determined as it has to contain all the microstructural information needed to characterize the interrelationship between both transport properties.

The purpose of this paper is to test the predictions of Eq. 3 against original experimental and microstructural data obtained for three different types of sandstone described in Section 2.1. More specifically, we test the models proposed by Walsh and Brace (1984), Guéguen and Dienes (1989), and Katz and Thompson (1986, 1987) with shape factors (c) and length scales $(L)$ listed in Table 1.

Furthermore, we compare Eq. 3 with an established empirical relationship between $k$ and $F$ (Eq. 4; e.g. Brace, 1977; Walsh and Brace, 1984 and references cited therein) that has been obtained from investigations on the pressure dependence of the coupled transport properties:

$$
k=c L_{E}^{2} \frac{1}{F^{r}},
$$

where $r$ denotes an empirical, rock dependent parameter following the notation in Walsh and Brace (1984). The subscript $E$ has been introduced to distinguish between both length scales defined within the respective relationship.

Section 2 outlines the experimental and microstructural procedures applied. In Section 3 the results obtained from both investigations are presented and the comparison between original data and the predictions of the scaling models is performed. In Section 4 the outcome is analysed in detail for each of the models tested. This section also emphasizes the conceptual difference between physical (Eq. 3) and empirical (Eq. 4) $k-F$ relationships. 
Section 5 summarized the principal findings of this study by means of some concluding remarks.

\section{Experimental and Microstructural Methodology}

\subsection{Sample Material and Fluid}

For the experiments three different types of sandstone samples were chosen: (1)

Fontainebleau sandstone, a pure quartz arenite quarried from an outcrop near Fontainebleau, France. This rock has extensively been used in previous studies aiming at the morphology and physical properties of sandstones (e.g. David et al., 1993; Auzerais et al., 1996; Coker et al., 1996; Cooper et al., 2000). (2) Flechtinger sandstone, a Lower Permian (Rotliegend) sedimentary rock quarried from an outcrop near Flechtingen, Germany. (3) Eberswalder sandstone, a Lower Permian (Rotliegend) rock cored during drilling of a prospective gas well (Eb2/76) at Eberswalde, Germany. The two Rotliegend samples are arcosic litharenites containing varying amounts of quartz $(55-65 \%)$, feldspars $(15-20 \%)$, and rock fragments, mainly of volcanic origin $(20-25 \%)$. In addition, smaller amounts of clays are present, predominantly illite and chlorite. The specimens were cylindrical in shape having a diameter of $30 \mathrm{~mm}$ and a length of $40 \mathrm{~mm}$ (Fontainebleau and Flechtinger) or $38.3 \mathrm{~mm}$ (Eberswalder). The dry mass of the specimens was $69.25 \mathrm{~g}$ (Fontainebleau), $68.36 \mathrm{~g}$ (Flechtinger), and 67.54 g (Eberswalder).

To enable electrical conductivity measurements 0.1 molar $\mathrm{NaCl}$-solution was used as the pore fluid. The electrical conductivity of this fluid $\left(\sigma_{f l}\right)$ at $25^{\circ} \mathrm{C}$ is $10.8 \mathrm{mS} / \mathrm{cm}$ and was measured with a hand held conductivity meter (WTW Multi 340i with TetraCon 325 conductivity probe). Prior to setting up the specimen assembly the samples were vacuumsaturated with this fluid. The comparison between both dry and wet sample mass yields the fluid mass within the (connected) pore space, thus the (connected) pore volume, and finally 
101 the (connected) porosity $\left(\varphi_{s}\right)$. The density of the fluid at $20^{\circ} \mathrm{C}$ and ambient pressure was

102 assumed to be equal to that of pure water $\left(0,998 \mathrm{~g} / \mathrm{cm}^{3}\right)$.

2.2 Experimental Procedure

The experiments were performed in a recently set up HPT-permeameter described in detail in Milsch et al. (2008). To avoid disturbance of the measurement by room temperature fluctuations the experimental temperature was maintained at $40( \pm 1){ }^{\circ} \mathrm{C}$. The dynamic viscosity of the fluid at this temperature is $653.4 \mu \mathrm{Pa} \mathrm{s}$ at a pressure of 5 MPa and was calculated with the NIST program REFPROP, again assuming pure water

110 properties. The electrical conductivity of the fluid at this temperature is $14.1 \mathrm{mS} / \mathrm{cm}$ and was

111 determined in previous temperature stepping experiments yielding a linear temperature

112 coefficient of approximately $0.02 /{ }^{\circ} \mathrm{C}$. By comparison we found an excellent agreement with 113 the data in Revil et al. (1998) (regarding the temperature coefficient) as well as the predictions

114 of the Arps-Equation (Arps, 1953) and the experimental data in Sen and Goode (1992)

115 (regarding the fluid conductivity itself).

116 In connection with the definition of the formation factor in Section 1 similar

117 experiments with fluids of varying salt content implied that a contribution from surface

118 conductivity to the actual overall sample conductivity was small even for the Rotliegend

119 samples containing minor amounts of clays. For the Fontainebleau sandstone this in

120 agreement with the observations made by David et al. (1993). Surface conductivity has thus

121 reasonably been neglected for all samples tested in this study. The supporting data is

122 presented as part of the supplementary material (file "Surface Conductivity.doc").

The sample permeability $(k)$ was measured with a steady state method making direct use of Darcy's Law. The electrical conductivity $(\sigma)$ was determined in a four-electrode arrangement with a variable shunt resistor and silver paint rims at the samples as potential

126 electrodes (see Milsch et al., 2008 for more details on both methodologies). Both transport 
127 properties were measured simultaneously. To investigate the relative changes of both

128 parameters effective pressure ramping was performed by successively increasing and

129 decreasing both confining and pore pressure. The pressures were varied from 10 to $50 \mathrm{MPa}$

$130\left(p_{c}\right)$ and 5 to $45 \mathrm{MPa}\left(p_{p}\right)$, respectively. Three full cycles and thus 12 individual ramps were

131 conducted for each sample. In contrast to electrical conductivity which can be determined

132 continuously during pressure ramping, permeability measurements have to be performed

133 stepwise. Depending on the sample permeability 5 to 10 measurements have been taken along

134 each ramp at effective pressure intervals ranging from 2.5 to $15 \mathrm{MPa}$.

\subsection{Microstructural Methodology}

Subsequent to each test thin sections were prepared. Two on the opposing faces of the specimen and one along the core. The sections were saturated with blue epoxy to allow 2D image analysis to be performed on binary images (Zeiss Axioplan with Axiocam and KSRun).

140 For a significant statistics approximately 1000 pores were evaluated for each section in two

141 different magnifications of 25x and 100x. Among a variety of other pore structural parameters

142 the image analysis program yields the measured pore radius distribution as a function of the

143 (total) cumulative porosity as well as an average pore radius. The minimum resolvable pore

144 radius is defined by the analysis program and is dependent on the magnification chosen: 6.5

$145 \mu \mathrm{m}$ at $25 \mathrm{x}$ and $1.7 \mu \mathrm{m}$ at $100 \mathrm{x}$. A description of the image analysis procedure has been placed

146 into the supplementary materials section (file "Image Analysis.doc").

147 In addition, mercury porosimetry (WS2000, Fisons Instruments) was performed after

148 the experiments on broken parts of the samples having a volume of approximately 1 to $2 \mathrm{~cm}^{3}$

149 each. Mercury porosimetry assumes a local cylindrical geometry for all parameters derived

150 and is based on the intrusion of a non-wetting fluid $(\mathrm{Hg})$ at a progressively increased pressure

151 of up to $200 \mathrm{MPa}$ and application of the Washburn Equation: $p_{c a p}=-4 \gamma \cos \theta / d$, where $p_{\text {cap }}$ is

152 the capillary pressure, $\gamma$ is the surface tension $(485 \mathrm{mN} / \mathrm{m}), \theta$ is the contact angle $\left(141.3^{\circ}\right)$, and 
$153 d$ is the local diameter of the pore space (e.g. Van Brakel et al., 1981). This independent

154 method also yields a pore radius distribution of the samples as a function of the (connected)

155 cumulative porosity as well as an average pore radius. In addition, the specific inner surface

156 distribution is calculated from the mercury injection curve. In contrast to 2D image analysis

157 the pore radius in that case designates the throat radius that relates to an individual injection

158 pressure. The minimum resolvable pore radius (at $200 \mathrm{MPa}$ maximum injection pressure) is

$159 \quad 3.7 \mathrm{~nm}$.

160

\section{Results}

162

\subsection{Experiments}

Table 2 displays an overview of the experimental sample properties, permeability $\left(k_{0}\right)$ and electrical conductivity $\left(\sigma_{0}\right)$, at starting conditions which were a confining pressure of 10 $\mathrm{MPa}$, a pore pressure of $5 \mathrm{MPa}$, and a temperature of $40^{\circ} \mathrm{C}$. The formation factor of the samples $\left(F_{0}\right)$ is shown in addition. The porosity $\left(\varphi_{s}\right)$ has been determined at ambient conditions by fluid saturation as described above. One notices that the Fontainebleau sandstone does not follow the parameter systematics of the two Rotliegend samples implying significant differences in morphology: It has a significantly higher permeability at the lowest conductivity and an intermediate porosity. It is also worth to note that in the present case a variation in permeability over three orders of magnitude relates only to a variation in conductivity by a factor of approximately three.

To present the dependence of the respective transport property on effective pressure

174 for all three samples in one figure it is convenient to perform a normalization with its starting value $\left(k_{0}\right.$ or $\left.\sigma_{0}\right)$. Figure 1a and $\mathbf{1 b}$ show the measured normalized permeability and electrical conductivity, respectively as a function of effective pressure. Absolute values can then be obtained from the respective figure and Table 2. For each of the rocks the figures display an average of all measurements taken during effective pressure ramping. The related error 
margins regarding the maximum upper and lower departure from the mean are discussed in

180 Section 3.3. Both transport properties are sensitive to changes in effective pressure. The sensitivity increases from the Fontainebleau over the Flechtinger to the Eberswalder sandstone. Furthermore, for all sandstones the sensitivity decreases with increasing effective pressure. The percental changes of both transport properties are closely related for the

184 Fontainebleau and the Flechtinger sandstones. In contrast, for the Eberswalder sandstone the

185 decrease in permeability at lower effective pressures is significantly more pronounced than the decrease in electrical conductivity. The respective approximately linear or bilinear dependence becomes evident when the normalized permeability is displayed as a function of the normalized electrical conductivity (Figure 1c).

\subsection{Microstructure}

The principal results of the microstructural investigations with 2D image analysis and mercury porosimetry are compiled in Table 3. The porosities determined with 2D image analysis $\left(\varphi_{2 D}\right)$ are strongly dependent on the chosen magnification of the microscope. This

194 could be due to cutting effects at the edges of the binary image becoming more important at 195 greater magnifications or resolution deficites at smaller magnifications. Depending on the magnification, the porosities also significantly differ from the ones obtained by both fluid saturation $\left(\varphi_{s}\right)$ and mercury porosimetry $\left(\varphi_{H g}\right)$. In contrast, $\varphi_{s}$ and $\varphi_{H g}$ are always in rather good agreement. The reliability of these (connected) porosities is supported by a comparison of the Fontainbleau dry bulk density with the density of quartz. The (total) porosity value so 200 obtained $(7.5 \%)$ is in excellent agreement with the two others. The table clearly indicates the differences in the average pore radii obtained by both methods. Naturally, the average pore throat $\left(r_{A, H g}\right)$ is significantly smaller than the pore itself $\left(r_{A, 2 D}\right)$. In both cases the average pore radius decreases from the Fontainebleau over the

204 Flechtinger to the Eberswalder sandstone. In contrast, the specific inner surface $\left(A_{H g}\right)$ of the 
205 Fontainebleau sandstone is significantly smaller than the ones of the two Rotliegend samples.

206 The pore radius distribution from mercury porosimetry (Figure 2a) indicates that is due to the 207 rather discrete and large pore radius of the Fontainebleau sandstone. This contrasts the 208 distribution of the two Rotliegend samples implying significant morphological differences. 209 Their larger specific inner surfaces (Figure $2 \mathbf{b}$ ) are principally due to contributions from pore 210 radii between $0.2-2.0 \mu \mathrm{m}$.

211 Assuming a cylindrical geometry the specific inner surface (relative to the pore

212 volume) can also be calculated directly from the average pore radii obtained by both methods: $213 A=2 / r_{A}$ (e.g. Guéguen and Palciauskas, 1994; p. 29). The values obtained in $\left[10^{6} 1 / \mathrm{m}\right]$ are 214 (2D; Hg): 0.092; 0.282 (Fontainebleau), 0.139; 1.538 (Flechtinger), and 0.163; 5.0

215 (Eberswalder), respectively. This can be compared to the cumulative mercury porosimetry 216 data from above also expressed in $\left[10^{6} 1 / \mathrm{m}\right]: 7.65$ (Fontainebleau), 34.64 (Flechtinger), and 21756.61 (Eberswalder), respectively. It is implied that significant differences in specific inner 218 surface can arise from (1) the respective geometrical methodology (pore radius versus pore 219 throat radius) and (2) the respective mathematical procedure (averaging versus cumulation). For documentation purposes micrographs of each sample have been placed into the 221 supplementary materials section (file "Microstructure.doc").

3.3 Analysis of errors introduced by the experiments and microstructural investigations Generally, absolute values of electrical conductivity are more precise than those of permeability. However, it showed that uncertainties in permeability and electrical conductivity related to the measurement itself (e.g. sensor noise, pump servo controller issues, etc.) are less significant than differences between values from one pressure ramp to another at nominally identical effective pressure conditions. The curves in Figs. 1a and $1 \mathrm{~b}$ are therefore in fact hysteresis-type bands that are presumably the result of time dependent microstructural adjustments to changes in effective pressure. A detailed investigation of this effect is beyond 
the scope of this study. The "width" of this band in terms of a minimum and maximum

232 departure from the mean is $\pm 12 \%(k$, Fontainebleau $), \pm 8 \%(k$, Flechtinger $), \pm 10 \%(k$,

233 Eberswalder), $\pm 4 \%$ ( $\sigma$, Fontainebleau and Eberswalder), and $\pm 3 \%$ ( $\sigma$, Flechtinger $)$. In

234 comparison, errors introduced in connection with a temperature or pressure adjustment of the 235 dynamic viscosity (to yield $k$ ) and the fluid conductivity (to yield $F$ ) are significantly smaller. 236 The precision of the average pore radii, the pore radius distribution, the specific inner 237 surface, and the cumulative porosity determined with both 2D image analysis and mercury 238 porosimetry rely on the respective analysis program as well as the implemented (idealized) 239 pore geometry (e.g. circles, cylinders). All values determined by an individual program have 240 been used as is. An estimate of the porosity accuracy related to the image analysis procedure 241 can be found in the supplementary materials section (file "Image Analysis.doc"). Additional 242 errors introduced could be due to a varying quality of the thin sections prepared, micro cracks introduced during cutting of the specimen or a microstructural anisotropy at the sample scale.

244 These errors are all hard to quantify. Errors that relate to the use of the mercury injection 245 curve in connection with the model by Katz and Thompson $(1986,1987)$ are discussed in 246 Section 4.2.

\subsection{Scaling Models}

Testing of the scaling models described in Section 1 and Table 1 has been performed by permutation of all three parameters measured (permeability, formation factor, and length scale) calculating one property from the two others. As the determination of the length scale by $2 \mathrm{D}$ image analysis and mercury porosimetry is performed at zero effective pressure the respective values of the permeability and the electrical conductivity measured were linearly extrapolated in Figures 1a and $1 \mathrm{~b}$. The obtained values $\left(k_{\text {ext }}\right.$ and $F_{\text {ext }}$, respectively $)$ are listed in

Table 4, where the conductivity has already been expressed as the formation factor. This table also compiles the measured length scales ( $m$ and $l_{c}$ in Table 1) used for the calculations: The 
hydraulic radius ( $m$; Walsh and Brace, 1984) was determined from the specific bulk volume 258 of the samples, the porosity in Table $3\left(\varphi_{H g}\right)$, and the specific inner surface in Table $3\left(A_{H g}\right)$.

259 The length scale $l_{c}$ was obtained from the inflection point of the mercury injection curve 260 following the procedure described in Katz and Thompson (1987). Finally, the average radii in 261 Table $3\left(r_{A, 2 D}\right.$ and $\left.r_{A, H g}\right)$ were tested as both the tube radius $r_{A}$ and the crack half aperture $w_{A}$ in 262 the model by Guéguen and Dienes (1989).

Table 5 displays the compilation of all values calculated from the scaling models and a comparison to the measured parameters expressed as a ratio (value calculated / value measured). An exact coincidence would thus result in a ratio of 1. It is evident from this table that none of the tested models can reproduce any of the experimentally or microstructurally determined parameters adequately within the error limits described in Section 3.3. Additionally, there is no clear preference for one of the models as for each of the rocks there is a different model with the closest numerical agreement.

Eq. 3 is very sensitive to errors introduced in connection with the respective length scale $(L)$ as the latter is dependent on a power of 2 . For example, the least deviation in $L$ 272 determined was $23 \%$ (Fontainebleau, model: Katz and Thompson, 1987) and relates to a 34 $273 \%$ departure in both transport properties. That means, if it is assumed that the respective 274 model is correct, that a length scale $l_{c}$ of $24.3 \mu \mathrm{m}$ instead of $19.8 \mu \mathrm{m}$ would have reproduced exactly either $k$ or $F$ determined experimentally. Else, if one trusts the length scale determined 276 from the mercury injection curve then the model contains flaws.

It is shown that models that are based on a tube geometry yield better results than 278 crack models, which in this study is solely related to the differences in the shape factor.

279 Furthermore, the compilation demonstrates that the use of the average throat radius as the 280 length scale in the model by Guéguen and Dienes (1989) yields better results than the average 281 pore radius itself. 
Assuming a cylindrical geometry one can also calculate the hydraulic radius $m_{2 D}$ from 283 the average pore radius $r_{A, 2 D}$ obtained by 2D image analysis: $m_{2 D}=r_{A, 2 D} / 2$ (e.g. Guéguen and 284 Palciauskas, 1994; p. 129). A comparison to the (cumulative) mercury porosimetry data $(m)$ in Table 4 yields: $m_{2 D} / m=87,256$, and 290 for the Fontainebleau, Flechtinger, and Eberswalder sandstone, respectively. In view of the results reported in Table 5 and with respect to the Walsh and Brace (1984) model this would yield severely inconsistent results for the two Rotliegend samples and no significant improvement for the Fontainebleau sandstone. The preceding results finally imply that injection methods (3D) could have significant advantages over optical procedures (2D) regarding an adequate microstructural rock characterization.

\section{Discussion}

4.1 Equivalent channel and statistical models

The observed inaccuracy of the models by Walsh and Brace (1984) and Guéguen and Dienes (1989) might be related to the assumption that both hydraulic and electrical transport follows the same flow paths (David, 1993; Van Siclen, 2002). In dependence on the type of rock this reasoning is supported by the mercury porosimetry measurements as outlined in Section 4.2 and furthermore by the analysis of Eq. 3 and Eq. 4 in Section 4.3. (1984) where the rather simple form of Eq. 3 was only obtained by the use of identical tortuosities $(\tau)$ for both transport properties. The (geometrical) parameter tortuosity, in most 303 simple terms, designates the ratio between the true and the apparent length of the flow path 304 (e.g. Bear, 1988). In the model by Guéguen and Dienes (1989) this assumption has been made implicitly through a common microstructural statistics as well as identical percolation factors

$306(f)$ for both transport properties. The parameter $f$ designates the fraction of connected pores 307 that span the sample over its entire length, or in terms of percolation theory "are part of an 
infinite path". Furthermore, two of the three microvariables introduced by Guéguen and

309 Dienes (1989) are suppressed whilst yielding Eq. 3.

Potentially, a separate calculation of $k$ and $F$ as in Guéguen and Dienes (1989) could

311 yield improved results with respect to the experimental data. As this requires a thorough

312 differentiated microstructural analysis that surpasses the capabilities of our image analysis

313 system, this approach has not been pursued further. In contrast, the independent expressions

314 for $k$ and $F$ in Walsh and Brace (1984) are under-determined as both contain the parameter

315 tortuosity. The tortuosity has to be derived from experiments unless improved 3D imaging

316 methods provide an alternative.

The equivalent channel model proposed by Van Siclen (2002) is a refinement of the model by Walsh and Brace (1984) with additional statistical components. The integrated $k-\sigma$ relationship distinguishes between hydraulic and electrical length scales and additionally contains separate hydraulic $\left(\tau_{h}\right)$ and electrical $\left(\tau_{e}\right)$ tortuosities. Finally, the model includes the empirical parameter $r$ (Eq. 4). Its derivation is certainly physically reasonable but the model itself is of limited practical use for several reasons: 1) it is impossible to distinguish between hydraulic and electrical length scales by means of conventional microstructural (optical) methods; 2) again, the tortuosity factors have to be determined experimentally. Thus, the parameters to be calculated from the model have to be known beforehand as $\tau_{h}$ is generally defined in connection with the Carman-Kozeny Equation (Eq. 11 in Walsh and Brace, 1984) and $\tau_{e}$ is defined by the product $(F \varphi)$, where $\varphi$ is the porosity (Eq. VIII.14 in Guéguen and Palciauskas, 1994); 3) the model still contains an adjustable parameter (r) that also has to be derived experimentally.

With regard to the electrical tortuosity it is worth to note the discrepancy between the

331 results of the present study and the assumption that "a lower electrical tortuosity should 332 reflect a more uniform microstructure that is favorably oriented to the electric field" (Guéguen and Palciauskas, 1994; p. 193). Calculation of $\tau_{e}$ for the three sandstones with $\varphi_{H g}$ from Table 
3343 and $F_{\text {ext }}$ from Table 4 yields: 8.6 (Fontainebleau), 3.6 (Flechtinger), and 3.0 (Eberswalder).

335 In contrast, the sample with the most uniform microstructure is evidently the Fontainebleau 336 sandstone (Figure 2a).

In view of the pore radius distributions in Figure 2a the samples display two extremes ranging from very discrete (Fontainebleau) to very broad (Flechtinger and Eberswalder). Both models rely conceptually on microstructural averaging. This significantly simplifies the

340 calculation but in turn could yield uncertainties in the adequate definition of the respective 341 length scale and might explain the limitations in precisely reproducing the experimentally 342 derived transport properties. On the other hand the microstructural methods themselves can 343 deliver both averaged and cumulative length scales. For example, assuming a cylindrical 344 geometry one can calculate the hydraulic radius $m_{a v}$ also from the average pore radius $r_{A, H g}$ 345 obtained by mercury porosimetry: $m_{a v}=r_{A, H g} / 2$ (e.g. Guéguen and Palciauskas, 1994; p. 129). 346 A comparison to the (cumulative) mercury porosimetry data $(m)$ in Table 4 yields: $m_{a v} / m=$

34728.2 , 23.2, and 9.5 for the Fontainebleau, Flechtinger, and Eberswalder sandstone, 348 respectively. With respect to the Walsh and Brace (1984) model the application of $m_{a v}$ would

349 yield severely inconsistent results for the two Rotliegend samples but interestingly would 350 provide an improvement for the Fontainebleau sandstone. This raises the question (1) whether an integration of continuous pore size classes into the framework of the model can deliver improved results and (2) if the optimal strategy for the microstructural determination of the length scale is dependent on the individual pore radius distribution.

4.2 Percolation models in connection with mercury porosimetry The model by Katz and Thompson $(1986,1987)$ has its theoretical foundations in the percolation (or critical path-) concept of Ambegaokar et al. (1971) and weights both hydraulic and electrical transport separately through trial solutions (Shante, 1977; Kirkpatrick, 1979) 
model in some more detail by an evaluation of their independent expressions for both $k(\mathbf{E q}$. 5) and $F$ (Eq. 6), respectively (Eq. (8) in Katz and Thompson, 1987):

$$
k=\frac{1}{89} \frac{\left(l_{\max }^{h}\right)^{3}}{l_{c}} \varphi S\left(l_{\max }{ }^{h}\right)
$$

Here, $\varphi$ is the sample porosity, $l_{c}$ is the length scale defined in Section $3.4, l_{\max }{ }^{e}$ is a pore diameter defining the optimum path for conductivity, $S\left(l_{\max }{ }^{e}\right)$ is the fractional volume of connected pore space involving pore width of size $l_{\max }{ }^{e}$ or larger, $l_{\max }{ }^{h}$ is a pore diameter defining the optimum path for permeability, and $S\left(l_{\max }{ }^{h}\right)$ is the fractional volume of connected pore space involving pore width of size $l_{\max }^{h}$ or larger.

All parameters so defined have been determined from the mercury injection data following the procedure described in Katz and Thompson (1987). In Table 6 these parameters are listed for the three sandstones together with the calculated values for both permeability $\left(k_{H g}\right)$ and the formation factor $\left(F_{H g}\right)$ as well as the experimental values $\left(k_{\exp }\right.$ and $\left.F_{\text {exp }}\right)$ at zero effective pressure for comparison. In this context we include the results obtained for a quartz rich Bentheimer sandstone of high porosity (26\%) (e.g. Klein and Reuschlé, 2003; Louis et al., 2003) that has undergone similar investigations performed by ourselves (unpublished data). It is evident from Table 6 that the coincidence between experimental and calculated values of both $k$ and $F$ is of varying quality depending on the rock. It ranges from an excellent agreement (for $F$, Bentheimer) to a factor of 20 (for $k$, Flechtinger). Generally, the values differ by a factor between 1.5 and 4.5. Errors made in the determination of the length scale $l_{c}$ 

98

affect all other parameters in Eqs. 5 and 6. This is specifically the case for highly permeable rocks that relate to large average pore widths where, at low injection pressures, choosing the correct inflection point of the injection curve bears some arbitrariness. However, this was not the case for the two Rotliegend samples. Consequently, there is no systematic evidence that the difference between experimental and calculated values is related to the precision of the microstructural procedure itself.

Eq. 5 and Eq. 6 (or Eq. (8) in Katz and Thompson, 1987) are in fact independent expressions for both transport properties that have their roots in an older concept described in Katz and Thompson (1986) (or Eq. (4) in Katz and Thompson, 1987). This model did not yet contain the saturation functions $S\left(l_{\max }^{e, h}\right)$, does not provide an independent description of the electrical conductivity (or the formation factor), but first yielded Eq. 3. The constant 1/89 in Eq. 5 has then been chosen to ensure consistency between both models. The respective expressions for both $k$ and $F$ can be rearranged to obtain the product $(k F)$. Eq. (4) and Eq. (8) in Katz and Thompson (1987) then yield:

$$
k F=\frac{1}{32}\left(l_{\max }{ }^{h}\right)^{2} \frac{\left(l_{c}-l_{\max }{ }^{h}\right)^{t}}{\left(l_{c}-l_{\max }{ }^{e}\right)^{t}}
$$

and

$$
\text { respectively, with parameter definitions as above. The percolation exponent } t \text { in three }
$$
dimensions is 1.9 (Fisch and Harris, 1978). One then obtains an expression (Eq. 9) for the ratio of the saturation functions $S\left(l_{\max }^{e, h}\right)$ in relation to the length parameters: 


$$
\frac{S\left(l_{\max }{ }^{h}\right)}{S\left(l_{\max }{ }^{e}\right)}=\frac{89}{32} \frac{l_{\max }{ }^{e}}{l_{\text {max }}^{h}} \frac{\left(l_{c}-l_{\text {max }}{ }^{h}\right)^{t}}{\left(l_{c}-l_{\text {max }}{ }^{e}\right)^{t}}
$$

An evaluation of Eq. 9 with the data listed in Table 6 shows that a close agreement

409 between both sides of the equation is only obtained for the Flechtinger and the Bentheimer sample whereas for the other two specimens there is a disagreement by a factor of approximately 2, eventually implying that their two models are not compatible. Eq. (6) in Katz and Thompson (1987) states that "for very broad pore size distributions" $l_{\max }{ }^{e}=0.34 l_{c}$ and $l_{\max }{ }^{h}=0.61 l_{c}$, thus $l_{\max }{ }^{e} / l_{\max }{ }^{h}=0.56$. Here, the sample with the broadest pore size 414 distribution (Flechtinger) yields a ratio $l_{\max }^{e} / l_{\max }^{h}$ of 0.73 (Table 6). Additionally, all ratios

$415 l_{\max }^{e, h} / l_{c}$ are larger than 0.34 and 0.61 , respectively. The above relations have therefore to be 416 viewed as a lower theoretical bound. Consequently, the shape factor $c=1 / 226$ in their model is not a constant but a rock dependent adjustable parameter and Eq. 3 yields incorrect results with respect to the experimental data.

4.3 Empirical relationships and effective pressure dependence As outlined below, the application of Eq. 3 for effective pressures other than zero is strictly only permissible when the concurrent evolution of the rock microstructure (respectively the characteristic length scale) is known. Since, so far, the microstructure cannot be accessed directly under in-situ conditions with the required precision, independent information on the poroelastic properties of the rock is required (e.g. Walsh, 1965; Nur and Byerlee, 1971; Berryman, 1992 and references cited therein). That means that the transport equations for both $k$ and $F$ would have to be complemented with a material dependent stress428 stain concept. For example, the hydraulic radius $m$ (Walsh and Brace, 1984) will be pressure 
calculated from an appropriate combination of bulk, solid, and fluid compressibilities and the

431 respective pressures. The poroelastic parameters have generally to be derived experimentally. Revil and Cathles (1999) propose an alternative approach. In connection with the physical scaling model established by Johnson et al. (1986) they derive a (semi-empirical) relationship between the related length scale, $\Lambda$ in their terminology, the cementation exponent $m$, an average grain size $R$, and the formation factor $F: \Lambda \approx R /(m F)$. Thus, after both parameters $m$ and $R$ have been determined, the effective pressure dependence of the length scale could be calculated from the measured effective pressure dependence of the formation 438 factor.

Eq. 4, in contrast to Eq. 3, is obtained when both $k$ and $F$ measured during pressure ramping are plotted against each other on a logarithmic scale (Figure 3a). The experiments then yield sample dependent parameters $r$ and $\left(c L_{E}^{2}\right)$ as the slope of the linear fit to the data

442 and the intersection with the y-axis, respectively. The product $\left(c L_{E}^{2}\right)$ is then a constant defining the "permeability" of one single equivalent channel for which $F=1$. The parameters $c$ and $L_{E}^{2}$ cannot be derived separately from the experiments but have to be calculated from

445 the model of choice. $L_{E}$, in this empirical approach, is thus a parameter with no true 446 microstructural meaning and has lost its character as a natural length scale. It is evident from 447 Figure 3 a that the parameter $r$ is not necessarily 1 as implied by Eq. 3 but can vary 448 significantly depending on the type of rock even for samples with a similar pore radius distribution. This indicates that other structural parameters (e.g. porosity, pore morphology, or 450 the proximity to the percolation threshold) could have a significant effect on the actual $k-F$ 451 relationship. Assuming predominantly cracks as the pore phase Walsh and Brace (1984) derived a phenomenological interpretation of the empirical parameter $r$ by relating the tortuosity factor $454(\tau)$ to the crack half aperture (w) (Eq. 10, or Eq. (20) in Walsh and Brace, 1984): 


$$
\frac{\tau^{2}}{\tau_{0}^{2}}=\left(\frac{w}{w_{0}}\right)^{-[(3-r) /(r-1)]}
$$

where $\tau_{0}$ and $w_{0}$ denote the respective arbitrary reference values. Walsh and Brace (1984)

concluded that $r$ is thus a measure of the sensitivity of the tortuosity to changes in crack aperture. Eq. 10 indicates that $r$ can range from 1 to 3 which is within the limits set by numerous previous experiments and also in agreement with our results. However, the conclusions drawn in this context are questionable: 1) that if $r=3$ this would imply that "tortuosity is independent of aperture" (Walsh and Brace, 1984); 2) that $r=1$ indicates the "proximity to the percolation threshold" (Guéguen and Dienes, 1989). Both statements are true in view of Eq. 10 but the Fontainebleau sandstone with $r$ close to 1 is definitely not in the proximity of the percolation threshold. In addition, the Eberswalder sandstone with $r$ close to 3 indicates the exact opposite as it is rather near the percolation threshold and contains predominantly crack porosity as indicated by the pronounced effective pressure dependence of its permeability (Figure 1a). The latter is an indirect effect related to an increased sample compressibility when the rock contains mostly cracks (Walsh, 1965). In other words, it requires less effort to close cracks than spherical pores. Introducing $\Lambda \approx R /(m F)$ from above (Revil and Cathles, 1999; Eq. (11)) into Eq. 3 with $L \equiv \Lambda$ and $c=1 / 2$ yields: $k=R^{2} /\left(2 m^{2} F^{3}\right)$ (Revil and Cathles, 1999; Eq. (12)). One notices that in this case $k$ obeys a power-law relationship with $F$. Comparison with Eq. 4 yields $r=3$ being a constant. As shown before, this only describes a particular case of 476 possible rock behaviour. Furthermore, $m$ and $R$ can reasonably be assumed pressure invariant 477 in agreement with the product $\left(c L_{E}^{2}\right)$ in Eq. 4. The difference, however, is that by $R$ being an average grain size, $\Lambda$ partly retains microstructural information whereas $L_{E}$ does not. 
These parameters are also listed in Table 7 as part of the supplementary material. With an

482 arbitrary choice for $c=1 / 8$ in connection with Hagen-Poiseuille's Law (e.g. Sutera and

483 Skalak, 1993), the calculation of $L_{E}$ finally yields: $13.03 \mu \mathrm{m}$ (Fontainebleau), $0.095 \mu \mathrm{m}$

484 (Flechtinger), and $3.38 \mu \mathrm{m}$ (Eberswalder). By comparing these results with the systematics of

485 the average radii in Table 3 it is clearly demonstrated that the empirically derived length scale

$486 L_{E}$ contains no true microstructural information. It should be noted that only a certain portion

487 of the curves in Figure $3 \mathrm{~b}$ is valid representing the physically possible states of the samples as

488 indicated by the arrows.

489 The significant difference between the length scales in Eq. 3 and Eq. 4 becomes

490 evident when the product $(k F)$ normalized by the starting values $\left(k_{0} F_{0}\right)$ is plotted as a

491 function of effective pressure (Figure 4a) and is compared to the pressure dependence of the

492 product $\left(k F^{\prime}\right)$ normalized by the starting values $\left(k_{0} F_{0}{ }^{r}\right)$ (Figure $\mathbf{4 b}$ ). Any departure of the

493 graphs from a value of 1 (Figure $4 a$ ) indicates a pressure dependence of the product $(k F)$ and

494 thus $\left(c L^{2}\right)$ in Eq. 3. The deviation is negligible for the Flechtinger sandstone $(<2 \%)$, small

495 for the Fontainebleau sandstone (5\%), and significant for the Eberswalder sandstone (50 \%).

496 This also implies that the percental pressure dependence of both transport properties is not

497 necessarily related one to one as already indicated in Figure 1c. Plotting the normalized

498 product $(k F)$ as a function of effective pressure thus provides a convenient method for

499 investigating (1) whether a pressure dependent adjustment of the length scale $L$ in Eq. 3

500 becomes necessary or not (Flechtinger), (2) if one single length parameter suffices

501 (Fontainebleau), and (3) if the introduction of separate length scales for the hydraulic and

502 electrical transport, respectively might potentially be more appropriate (Eberswalder).

503 In Figure $4 \mathrm{~b}$ all graphs remain close to 1 as the product $\left(c L_{E}{ }^{2}\right)$ is a constant by

504 definition as outlined above. Here, the pressure dependence of the microstructure is implicitly

505 contained within the empirical parameter $r$. The bulge of the graph of the Eberswalder

506 sandstone at lower effective pressures is due the bilinear behaviour of the sample (Figure 1c). 
507 A complete empirical description of this specimen thus requires a pressure dependent

508 adjustment of $r$ implying that this parameter is not necessarily a constant.

\section{Conclusions}

For three different types of sandstone (Fontainebleau, Flechtinger, and Eberswalder)

512 we tested three different models that relate the permeability $k$ of a rock to its electrical

513 conductivity $\sigma$ through characteristic length scales ([1] Walsh and Brace, 1984; [2] Guéguen

514 and Dienes, 1989; [3] Katz and Thompson, 1986; 1987). Testing was performed against

515 original experimental and microstructural data. By the choosing an appropriate fluid salinity,

516 the rock conductivity was ensured to be fluid dominated. Surface conductivity was proven to

517 be negligible in the present study.

518 It showed that none of the models was able to predict permeability within

519 experimental precision. Furthermore, there was no clear preference for one of the models

520 tested, implying that the appropriateness of an individual model is rock-type dependent. Thus,

521 the most promising modelling-strategy was not revealed.

It is concluded that mercury porosimetry provides a more reliable and useful

523 microstructural characterization than does 2D image analysis. Specifically, the use of an

524 average throat radius as the length scale yielded better results than an average pore radius

525 (model [2]).

526 In agreement with previous studies (e.g. David, 1993) we presented evidence that, in

527 dependence on the type of rock, hydraulic and electrical transport do not necessarily follow

528 the same flow paths. This implies transport property dependent tortuosities (model [1]) and

529 percolation factors (model [2]).

530 It was proven that the shape factor in model [3] is not a constant $(1 / 226)$ but a rock-

531 type dependent adjustable parameter. 
533 pressures enabled us to establish an empirical $k$ - $\sigma$ relationship for each of the sandstones (Eq.

534 4). The included empirical parameter $r$ took values between 1 and 3 in agreement with

535 previous studies. Furthermore, it showed that $r$ can vary with pressure, specifically when the

536 permeability of the sandstone is dominated by crack porosity. We interpret the empirical

537 parameter $r$ as a measure of the relative effect of pressure changes on the linked transport

538 properties. In turn, it can also be viewed as a qualitative indicator for the degree of

539 coincidence of hydraulic and electrical flow paths.

540 A comparison between the length scales in the physical models [1] - [3] and the one in

541 a purely empirical $k$ - $\sigma$ relationship yielded significant differences. The empirical length

542 parameter is a pressure independent constant and contains no true microstructural or physical

543 information. In contrast, the length scale in the models [1] - [3] is physically meaningful.

544 However, the application of these physical models at effective pressures other than zero

545 requires the concurrent evolution of the respective length scale to be characterized by either

546 (direct or indirect) calculation or improved microstructural methods.

\section{Acknowledgements}

Steffi Meyhöfer, GFZ Potsdam is thanked for her help with the mercury porosimetry measurements. We thank two anonymous reviewers for their very constructive comments that

552 helped to improve the manuscript. This research project was financially supported by the

553 Federal Ministry for the Environment, Nature Conservation, and Nuclear Safety under Grant 554 No. BMU 0329951B. 


\section{References}

559 Ambegaokar, V., Halperin, B.I., Langer, J.S., 1971. Hopping conductivity in disordered systems. Phys. Rev. B 4, 2612-2620.

Arps, J. J., 1953. The effect of temperature on the density and electrical resistivity of sodium chloride solutions. Petr. Trans. AIME 198, 327-330.

Auzerais, F.M., Dunsmuir, J., Ferréol, B.B., Martys, N., Olson, J., Ramakrishnan, T.S., Rothman, D.H., Schwartz, L .M., 1996. Transport in sandstone: A study based on three dimensional microtomography. Geophys. Res. Lett. 23 (7), 705-708.

Avellaneda, M., Torquato, S., 1991. Rigorous link between fluid permeability, electrical conductivity, and relaxation times for transport in porous media. Phys. Fluids A 3 (11), 2529-2540.

Bear, J., 1988. Dynamics of fluids in porous media. Dover Publ. Inc., Mineola, NY.

Berryman, J. G., 1992. Effective Stress for Transport Properties of Inhomogeneous Porous Rock. J. Geophys. Res. 97 (B12), 17409-17424.

Brace, W.F., 1977. Permeability from resistivity and pore shape. J. Geophys. Res. 82 (23), 3343-3349.

Coker, D.A., Torquato, S., Dunsmuir, J.H., 1996. Morphology and physical properties of Fontainebleau sandstone via a tomographic analysis. J. Geophys. Res. 101 (B8), 17497-17506.

Cooper, M.R., Evans, J., Flint, S.S., Hogg, A.J.C., Hunter, R.H., 2000. Quantification of detrital, authigenic and porosity components of the Fontainebleau sandstone: a comparison of conventional optical and combined scanning electron microscope-based methods of modal analyses. Spec. Publs. Int. Ass. Sediment. 29, 89-101.

Darcy, H., 1856. Les fontaines publique de la ville de Dijon. Dalmont, Paris.

David, C., 1993. Geometry of flow paths for fluid transport in rocks. J. Geophys. Res. 98, 12267-12278. 
David, C., Darot, M., Jeannette, D., 1993. Pore Structures and Transport Properties of Sandstone. Transp. Porous Med. 11, 161-177.

Fisch, R., Harris, A.B., 1978. Critical behavior of random resistor networks near the percolation threshold. Phys. Rev. B 18 (1), 416-420.

Guéguen, Y., Dienes, J., 1989. Transport Properties of Rocks from Statistics and Percolation. Math. Geol. 21 (1), 1-13.

Guéguen, Y., Palciauskas, V., 1994. Introduction to the physics of rocks. Princeton University Press, Princeton, NJ.

Johnson, D.L., Koplik, J., Schwartz, L.M., 1986. New Pore-Size Parameter Characterizing Transport in Porous Media. Phys. Rev. Lett. 57 (20), 2564-2567.

Katz, A.J., Thompson, A.H., 1986. Quantitative prediction of permeability in porous rock. Phys. Rev. B 34 (11), 8179-8181.

Katz, A.J., Thompson, A.H., 1987. Prediction of Rock Electrical Conductivity From Mercury Injection Measurements. J. Geophys. Res. 92 (B1), 599-607.

Kirkpatrick, S., 1979. Models of disordered materials, in: Balian, R., Maynard, R., Toulouse, G. (Eds.), Ill-Condensed Matter. North-Holland, Amsterdam, 323-403.

Klein, E., Reuschlé, T., 2003. A Model for the Mechanical Behaviour of Bentheim Sandstone in the Brittle Regime. Pure Appl. Geophys. 160, 833-849.

Louis, L., David, C., Robion, P., 2003. Comparison of the anisotropic behaviour of undeformed sandstones under dry and saturated conditions. Tectonophysics 370, $193-$ 212.

Martys, N., Garboczi, E.J., 1992. Length scales relating the fluid permeability and electrical conductivity in random two-dimensional model porous media. Phys. Rev. B 46 (10), 6080-6090. 
Milsch, H., Spangenberg, E., Kulenkampff, J., Meyhöfer, S., 2008. A new Apparatus for Long-term Petrophysical Investigations on Geothermal Reservoir Rocks at Simulated In-situ Conditions. Transp. Porous Med. 74, 73-85. doi:10.1007/s1 1242-007-9186-4.

Nur, A., Byerlee, J.D., 1971. An Exact Effective Stress Law for Elastic Deformation of Rock with Fluids. J. Geophys. Res. 76 (26), 6414-6419.

Ohm, G.S., 1826. Bestimmung des Gesetzes, nach welchem Metalle die Contaktelektricität leiten, nebst einem Entwurfe zu einer Theorie des Voltaischen Apparates und des Schweiggerschen Multiplicators, in: Schweigger, J.S.C., Schweigger-Seidel, W. (Eds.), Jahrbuch der Chemie und Physik, XVI. Band, 137-166.

Paterson, M.S., 1983. The equivalent channel model for permeability and resistivity in fluid saturated rocks - A reappraisal. Mech. Mater. 2 (4), 345-352.

Revil, A., Cathles III, L. M., 1999. Permeability of shaly sands. Water Resour. Res. 35 (3), $651-662$.

Revil, A., Cathles III, L. M., Losh, S., Nunn, J. A., 1998. Electrical conductivity in shaly sands with geophysical applications. J. Geophys. Res. 103 (B10), 23925-23936.

Sen, P. N., Goode, P. A., 1992. Influence of temperature on electrical conductivity on shaly sands. Geophysics 57 (1), 89-96.

Shante, V.K.S., 1977. Hopping conduction in quasi-one-dimensional disordered compounds. Phys. Rev. B 16 (6), 2597-2612.

Sutera, S.P., Skalak, R., 1993. The history of Poiseuille's Law. Annu. Rev. Fluid Mech. 25, 119.

Terzaghi, K.v., 1923. Die Berechnung der Durchlässigkeitsziffer des Tones aus dem Verlauf der hydrodynamischen Spannungserscheinungen. Sitzungsber. Akad. Wiss. Wien, Math. Naturwiss. K1., Abt. 2A, 132, 105-124.

Van Brakel, J., Modrý, S., Svatá, M., 1981. Mercury Porosimetry: State of the art. Powder Technology 29 (1), 1-12. 
634 Van Siclen, C.D., 2002. Equivalent channel network model for permeability and electrical conductivity of fracture networks. J. Geophys. Res. 107 (B6), 2106, doi:10.1029/2000JB000057.

637 Walsh, J.B., 1965. The Effect of Cracks on the Compressibility of Rock. J. Geophys. Res. 70 638 (2), 381-389.

639 Walsh, J.B., Brace, W.F., 1984. The Effect of Pressure on Porosity and the Transport $640 \quad$ Properties of Rock. J. Geophys. Res. 89 (B11), 9425-9431.

641 Wyllie, M.R.J., Rose, W.D., 1950. Some theoretical considerations related to the quantitative 642 evaluation of the physical characteristics of reservoir rock from electrical log data. Trans. Am. Inst. Mech. Eng. 189, 105-118. 
3 Figure 1: (a) Normalized permeability as a function of effective pressure. Normalization has been performed with the starting permeability $\left(k_{0}\right)$ in Table 2.

(b) Normalized electrical conductivity as a function of effective pressure. Normalization refers to the starting conductivity $\left(\sigma_{0}\right)$ in Table 2. For each individual sample and effective pressure the graphs display an average of all measurements taken. The error margins concerning the maximum and minimum departure from the mean are analysed in Section 3.3. The effective pressure sensitivity of both transport properties decreases with an increase in effective pressure and increases from the Fontainebleau over the Flechtinger to the Eberswalder sandstone.

(c) Normalized permeability from (a) as a function of the normalized electrical conductivity from (b). The Fontainebleau and the Flechtinger sandstones display an approximately linear relationship between both transport properties. In contrast, the Eberswalder sandstone shows a bilinear $k$ - $\sigma$ relationship in dependence of the effective pressure range. 
Figure 2: (a) Cumulative porosity as a function of the pore radius measured with mercury porosimetry. The two Rotliegend samples show a broad pore radius distribution, whereas it is rather discrete for the Fontainebleau sandstone.

(b) Cumulative specific inner surface as a function of the pore radius measured with mercury porosimetry. The comparatively small overall inner surface of the Fontainebleau sandstone relates to its large average pore dimensions.

Figure 3: $\quad$ (a) Logarithm of the measured permeability as a function of the logarithm of the related formation factor (from Figure 1). The linear fit through the data yields the adjustable parameters $r$ and $\left(c L_{E}^{2}\right)$ of the empirical $k$ - $F$ relationship (Eq. 4).

(b) Permeability as a function of the formation factor from both the experiments (dots) and Eq. 4 (lines). Only a certain portion of the graphs is valid relating to the physically possible states of the samples (arrows). 
Figure 4: $\quad$ (a) Normalized product $(k F)$ as a function of effective pressure. Normalization has been performed with the respective starting values $\left(k_{0}\right.$ and $\left.F_{0}\right)$ in Table 2. The departure of the graphs from a value of 1 (Fontainebleau and Eberswalder sandstones) indicates a pressure dependent length scale $L$ in Eq. 3.

(b) Normalized product $\left(k F^{\prime}\right)$ as a function of effective pressure with the parameter $r$ from Figure 3a. The graphs remain close to 1 as in the empirical relationship Eq. 4 the product $\left(c L_{E}^{2}\right)$ is a constant by definition and the pressure dependence of the related transport properties $k$ and $F$ is accounted for by the parameter $r$. The graph of the Eberswalder sandstone indicates that a complete empirical description of this specimen requires a pressure dependent adjustment of $r$ implying that this parameter is not necessarily a constant. 


\section{Figures}

\section{Figure 1:}
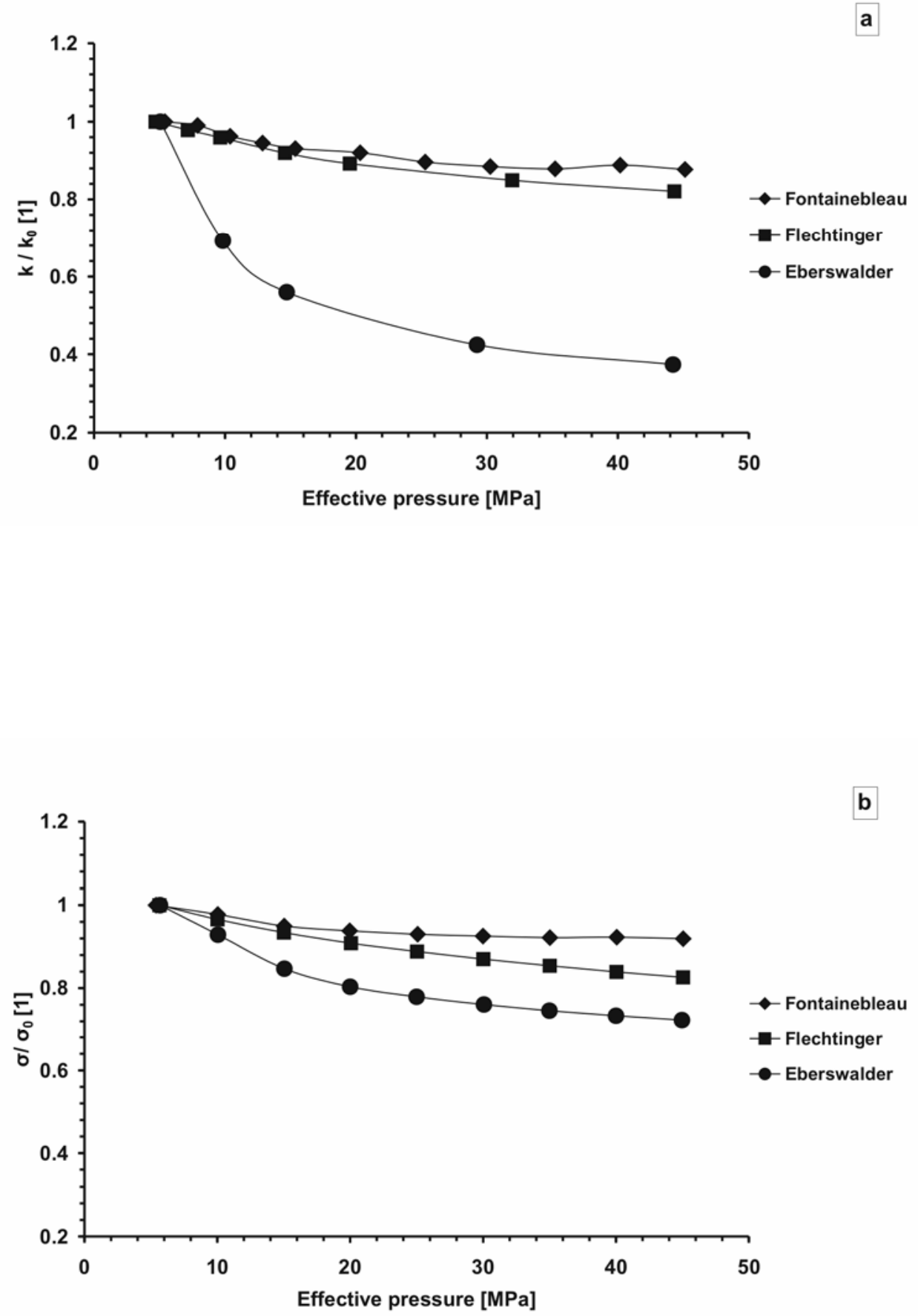
Figure 1 (cont.):

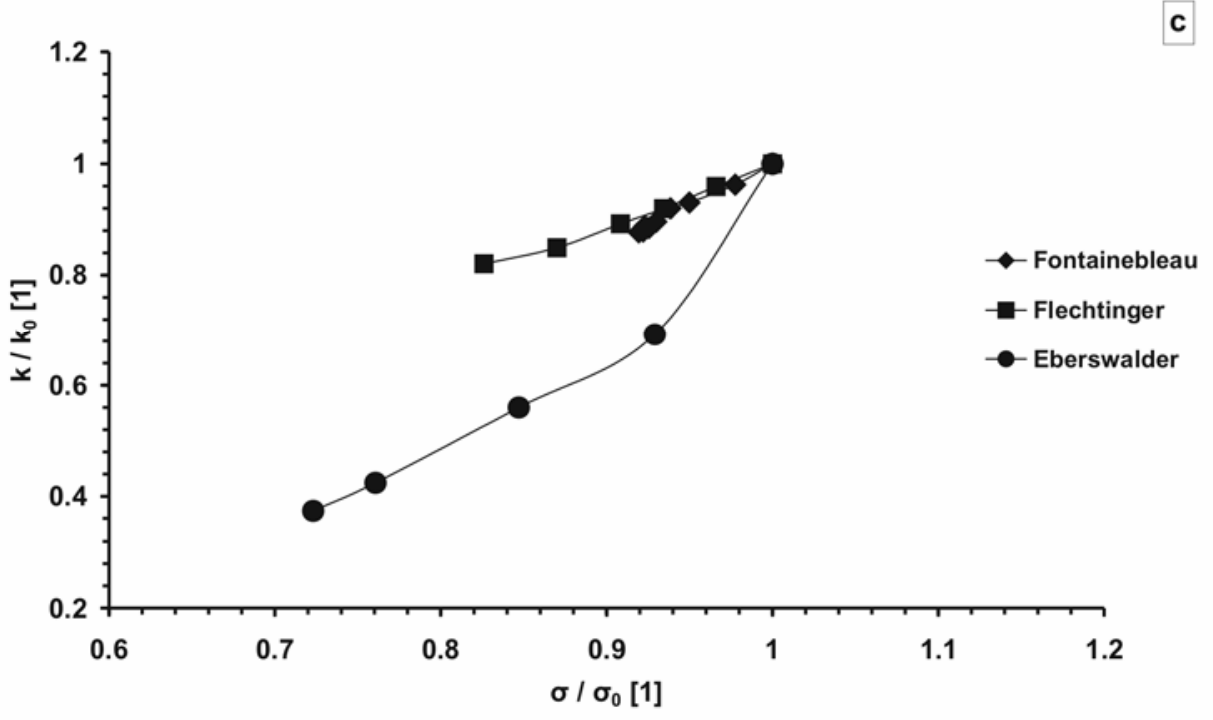




\section{Figure 2}

a
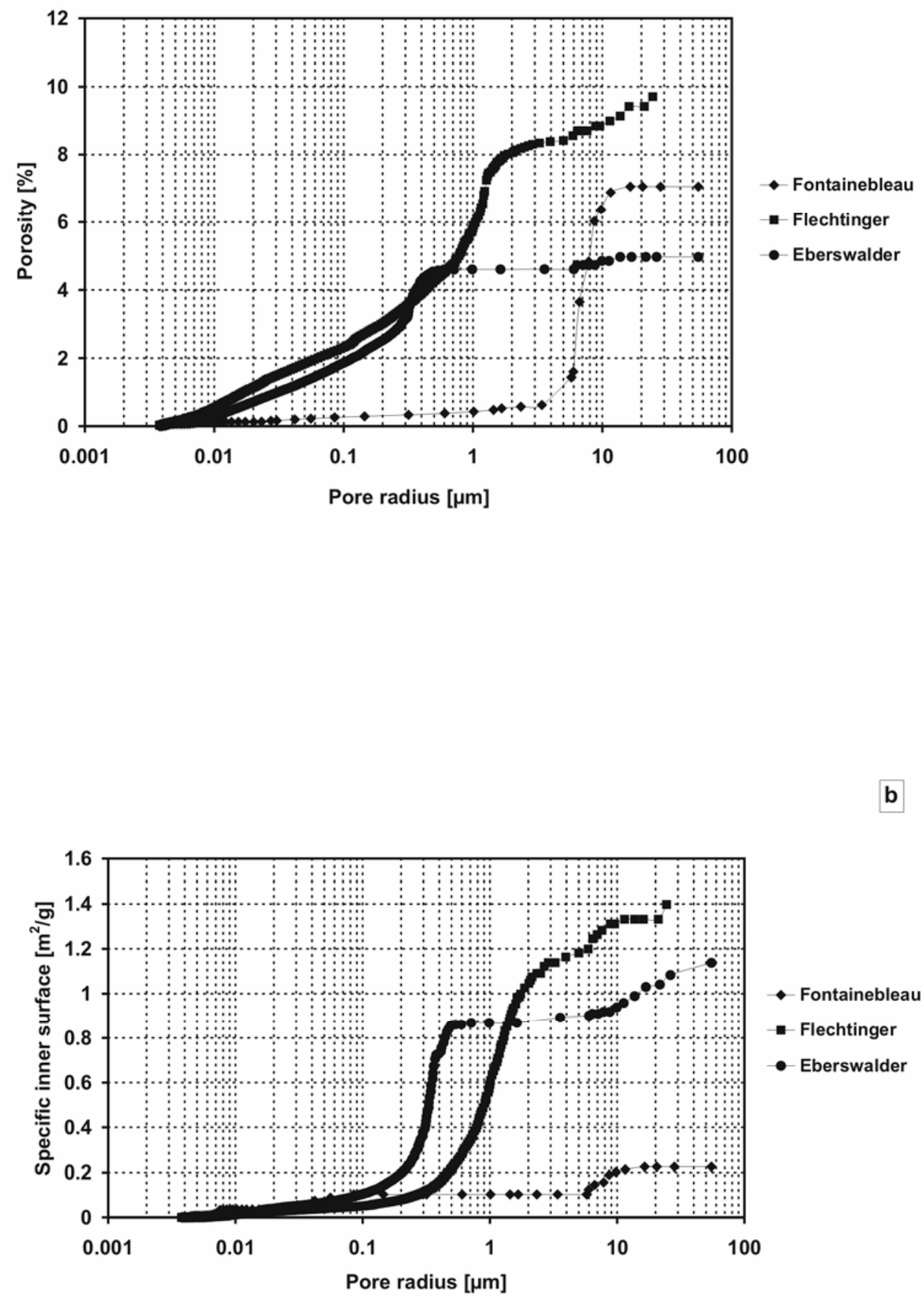
Figure 3
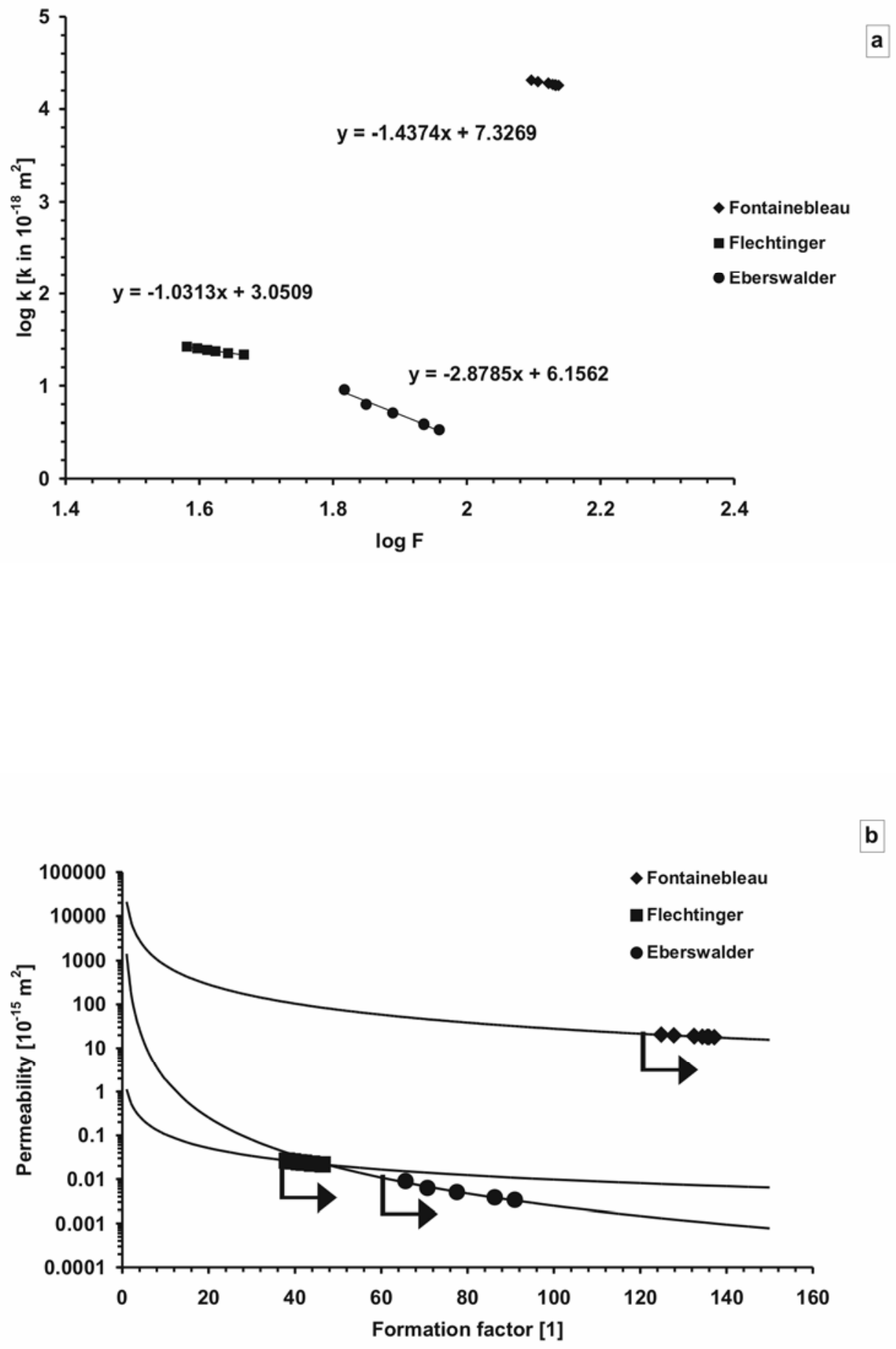
Figure 4

a

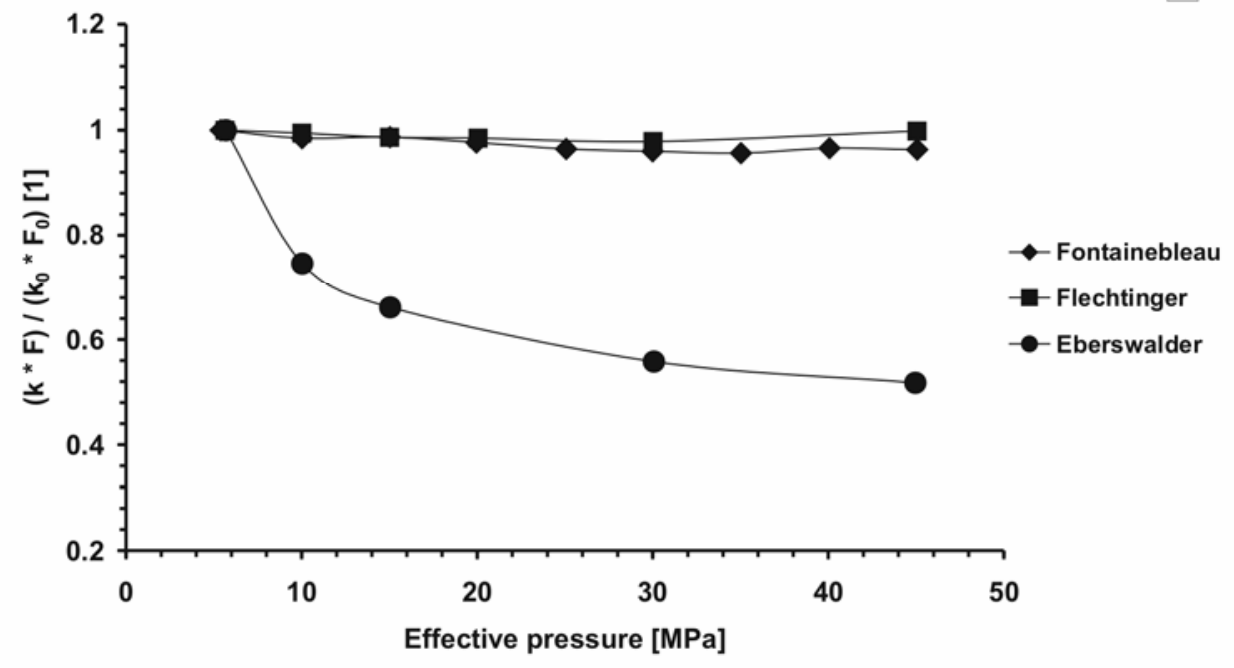

b

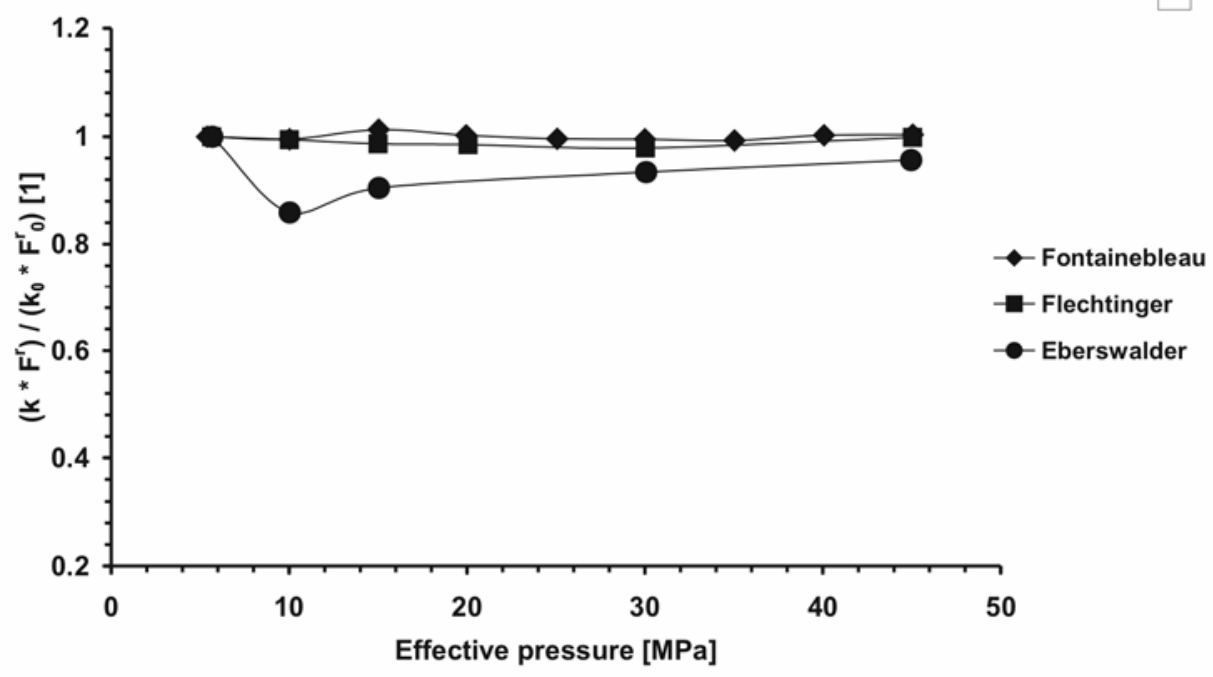




\section{Tables}

Table 1: Parameters of the scaling models investigated.

\begin{tabular}{ccc}
\hline Model & $c[1]$ & $L[\mu \mathrm{m}]$ \\
\hline \hline $\begin{array}{c}\text { Hydraulic Radius } \\
\text { (Walsh and Brace, 1984) }\end{array}$ & $\begin{array}{c}1 / 2 \text { (tube) } \\
1 / 3 \text { (crack) }\end{array}$ & $m=\left(V_{p} / A_{p}\right)$ \\
\hline \hline $\begin{array}{c}\text { Statistics and Percolation } \\
\text { (Guéguen and Dienes, 1989) }\end{array}$ & $\begin{array}{c}r_{A}(\text { tube) } \\
w_{A}(\mathrm{crack})\end{array}$ \\
\hline \hline $\begin{array}{c}\text { Mercury Porosimetry (tube) } \\
\text { (Katz and Thompson, 1986; 1987) }\end{array}$ & $1 / 226$ & $l_{c}$ \\
\hline \hline
\end{tabular}

$c$ : shape factor; $L$ : length scale;

$m$ : hydraulic radius; $V_{p}$ : (total) pore volume; $A_{p}$ : (total) inner pore surface;

$r_{A}$ : average tube radius; $w_{A}$ : average crack half aperture;

$l_{c}$ : length scale defined by Katz and Thompson $(1986,1987)$.

Table 2: Sample properties at starting conditions:

confining pressure $=10 \mathrm{MPa}$; pore pressure $=5 \mathrm{MPa}$; Temperature $=40^{\circ} \mathrm{C}$.

\begin{tabular}{ccccc}
\hline Sample & $\varphi_{s}[\%]$ & $k_{0}\left[10^{-15} \mathrm{~m}^{2}\right]$ & $\sigma_{0}[\mathrm{mS} / \mathrm{cm}]$ & $F_{0}[1]$ \\
\hline Fontainebleau & 7.5 & 20.6 & 0.113 & 124.9 \\
\hline Flechtinger & 9.0 & 0.027 & 0.370 & 38.1 \\
\hline \hline Eberswalder & 4.0 & 0.0091 & 0.215 & 65.6 \\
\hline
\end{tabular}

$\varphi_{s}$ : sample porosity measured by saturation at zero effective pressure;

$k_{0}$ : permeability;

$\sigma_{0}$ : electrical conductivity;

$F_{0}$ : formation factor. 
Table 3: Results of the microstructural investigations.

\begin{tabular}{|c|c|c|c|c|c|}
\hline Sample & $\varphi_{2 D}(25 / 100 \mathrm{x})[\%]$ & $r_{A, 2 D}[\mu \mathrm{m}]$ & $\varphi_{H g}[\%]$ & $r_{A, H g}[\mu \mathrm{m}]$ & $A_{H g}\left[\mathrm{~m}^{2} / \mathrm{g}\right]$ \\
\hline Fontainebleau & $13.7 / 16.5$ & 21.7 & 7.1 & 7.1 & 0.23 \\
\hline Flechtinger & $5.0 / 12.0$ & 14.4 & 9.7 & 1.3 & 1.4 \\
\hline Eberswalder & $2.1 / 4.0$ & 12,3 & 5.0 & 0.4 & 1.14 \\
\hline
\end{tabular}

$\varphi_{2 D}$ : sample porosity measured by $2 \mathrm{D}$ image analysis at given magnifications;

$r_{A, 2 D}$ : average pore radius determined with $2 \mathrm{D}$ image analysis;

$\varphi_{H g}$ : sample porosity measured by mercury porosimetry;

$r_{A, H g}$ : average pore radius determined with mercury porosimetry;

$A_{H g}$ : specific inner pore surface determined with mercury porosimetry.

Table 4: Parameters used for testing of the scaling models by Walsh and Brace (1984) and Katz and Thompson (1986, 1987).

\begin{tabular}{ccccc}
\hline Sample & $k_{\text {ext }}\left[10^{-15} \mathrm{~m}^{2}\right]$ & $F_{\text {ext }}[1]$ & $m[\mu \mathrm{m}]$ & $l_{c}[\mu \mathrm{m}]$ \\
\hline Fontainebleau & 21.6 & 121.2 & 0.126 & 19.77 \\
\hline \hline Flechtinger & 0.028 & 37.0 & 0.028 & 2.50 \\
\hline Eberswalder & 0.013 & 59.6 & 0.021 & 0.65 \\
\hline
\end{tabular}

$k_{\text {ext }}:$ permeability from Figure 1a extrapolated to zero effective pressure;

$F_{\text {ext }}$ : formation factor from Figure $1 \mathrm{~b}$ extrapolated to zero effective pressure;

$m$ : hydraulic radius (see definition in Table 1);

$l_{c}$ : length scale determined from mercury injection curve. 
Table 5: Testing of the respective scaling model - compilation of results.

In each cell the respective value calculated from the scaling model is shown on the left and the comparison to the measured parameters expressed as a ratio $(R)$ is shown on the right. Underlined values indicate the best agreement with the experimental data.

\begin{tabular}{|c|c|c|c|}
\hline Sample/Model & $F[1] / R[1]$ & $k\left[10^{-15} \mathrm{~m}^{2}\right] / R[1]$ & $m, l_{c}, r_{A}, w_{A}[\mu \mathrm{m}] / R[1]$ \\
\hline \multicolumn{4}{|l|}{ Fontainebleau } \\
\hline WB tube & $0.366 / 0.003$ & $0.065 / 0.003$ & $2.28 / 18.1$ \\
\hline WB crack & $0.244 / 0.002$ & $0.043 / 0.002$ & $2.80 / 22.2$ \\
\hline KT & $\underline{80.0 / 0.660}$ & $\underline{14.3 / 0.660}$ & $\underline{24.3 / 1.23}$ \\
\hline GD (tube 2D) & $2724 / 22.5$ & $486 / 22.5$ & $4.58 / 0.211$ \\
\hline GD (crack 2D) & $11628 / 95.9$ & $2071 / 95.9$ & $2.22 / 0.102$ \\
\hline GD (tube $\mathrm{Hg}$ ) & $291 / 2.4$ & $52.0 / 2.4$ & $4.58 / 0.645$ \\
\hline GD (crack Hg) & $1244 / 10.3$ & $222 / 10.3$ & $2.22 / 0.313$ \\
\hline \multicolumn{4}{|l|}{ Flechtinger } \\
\hline WB tube & $14.2 / 0.384$ & $0.011 / 0.384$ & $0.045 / 1.61$ \\
\hline WB crack & $9.4 / 0.254$ & $0.007 / 0.254$ & $0.056 / 2.0$ \\
\hline KT & $994 / 26.9$ & $0.747 / 26.9$ & $0.48 / 0.192$ \\
\hline GD (tube 2D) & $931911 / 25186$ & $700 / 25186$ & $0.091 / 0.006$ \\
\hline GD (crack 2D) & $3976154 / 107464$ & 2988 / 107464 & $0.044 / 0.003$ \\
\hline GD (tube $\mathrm{Hg}$ ) & $7595 / 205$ & $5.71 / 205$ & $0.091 / 0.070$ \\
\hline GD (crack Hg) & $32405 / 876$ & $24.3 / 876$ & $0.044 / 0.034$ \\
\hline \multicolumn{4}{|l|}{ Eberswalder } \\
\hline WB tube & $17.7 / 0.297$ & $0.004 / 0.297$ & $0.039 / 1.86$ \\
\hline WB crack & $11.8 / 0.198$ & $0.003 / 0.198$ & $0.048 / 2.3$ \\
\hline KT & $147 / 2.5$ & $\underline{0.031 / 2.5}$ & $\underline{0.41 / 0.631}$ \\
\hline GD (tube 2D) & $1488400 / 24973$ & $317 / 24973$ & $0.078 / 0.006$ \\
\hline GD (crack 2D) & $6350507 / 106552$ & $1353 / 106552$ & $0.038 / 0.003$ \\
\hline GD (tube Hg) & $1574 / 26.4$ & $0.335 / 26.4$ & $0.078 / 0.195$ \\
\hline GD (crack Hg) & $6716 / 112.7$ & $1.43 / 112.7$ & $0.038 / 0.095$ \\
\hline
\end{tabular}

$F$ : formation factor;

$k$ : permeability;

$m, l_{c}, r_{A}, w_{A}$ : length scale of the respective scaling model (see Table 1 for definitions);

WB: Walsh and Brace (1984);

KT: Katz and Thompson $(1986,1987)$;

GD: Guéguen and Dienes (1989). 
Table 6: Evaluation of the independent constitutive equations for permeability (Eq. 5) and formation factor (Eq. 6) (Katz and Thompson, 1987).

\begin{tabular}{ccccc}
\hline Sample & Fontainebleau & Flechtinger & Eberswalder & Bentheimer \\
\hline & & & & \\
\hline$\varphi_{H g}[\%]$ & 7.1 & 9.7 & 5.0 & 26.4 \\
\hline & & & & \\
$l_{c}[\mu \mathrm{m}]$ & 19.77 & 2.50 & 0.65 & 38.23 \\
$l_{\max }[\mu \mathrm{m}]$ & 11.53 & 1.46 & 0.38 & 26.01 \\
$S\left(l_{\max }{ }^{e}\right)[1]$ & 0.90 & 0.31 & 0.28 & 0.57 \\
$l_{\max }^{h}[\mu \mathrm{m}]$ & 13.31 & 1.99 & 0.55 & 30.83 \\
$S\left(l_{\max }{ }^{h}\right)[1]$ & 0.73 & 0.17 & 0.15 & 0.45 \\
& & & & \\
\hline$k_{H g}\left[10^{-15} \mathrm{~m}^{2}\right]$ & 69.3 & 0.59 & 0.021 & 1031 \\
$F_{H g}[1]$ & 27.1 & 56.9 & 122.7 & 9.8 \\
\hline \multicolumn{5}{c}{} \\
\hline$k_{\text {exp }}\left[10^{-15} \mathrm{~m}^{2}\right]$ & 21.6 & 0.028 & 0.013 & $\approx 650$ \\
$F_{\exp }[1]$ & 121.2 & 37.0 & 59.6 & 10,2 \\
\hline
\end{tabular}

$\varphi_{H g}$ : sample porosity measured by mercury porosimetry (from Table 3 );

$l_{c}$ : length scale determined from mercury injection curve (from Table 4);

$l_{\max } e^{e}$ : pore diameter defining the optimum path for conductivity;

$S\left(l_{\max }{ }^{e}\right)$ : fractional volume of connected pore space involving pore width $\geq l_{\max }{ }^{e}$; $l_{\max }^{h}$ : pore diameter defining the optimum path for permeability;

$S\left(l_{\max }{ }^{h}\right)$ : fractional volume of connected pore space involving pore width $\geq l_{\max }{ }^{h}$;

$k_{H g}$ : permeability calculated from Eq. 5;

$F_{H g}$ : formation factor calculated from Eq. 6;

$k_{\text {exp }}$ : experimental permeability at zero effective pressure (from Table 4);

$F_{\text {exp }}$ : experimental formation factor at zero effective pressure (from Table 4). 
Fontainebleau sandstone: plain light (top), crossed nicols (bottom)
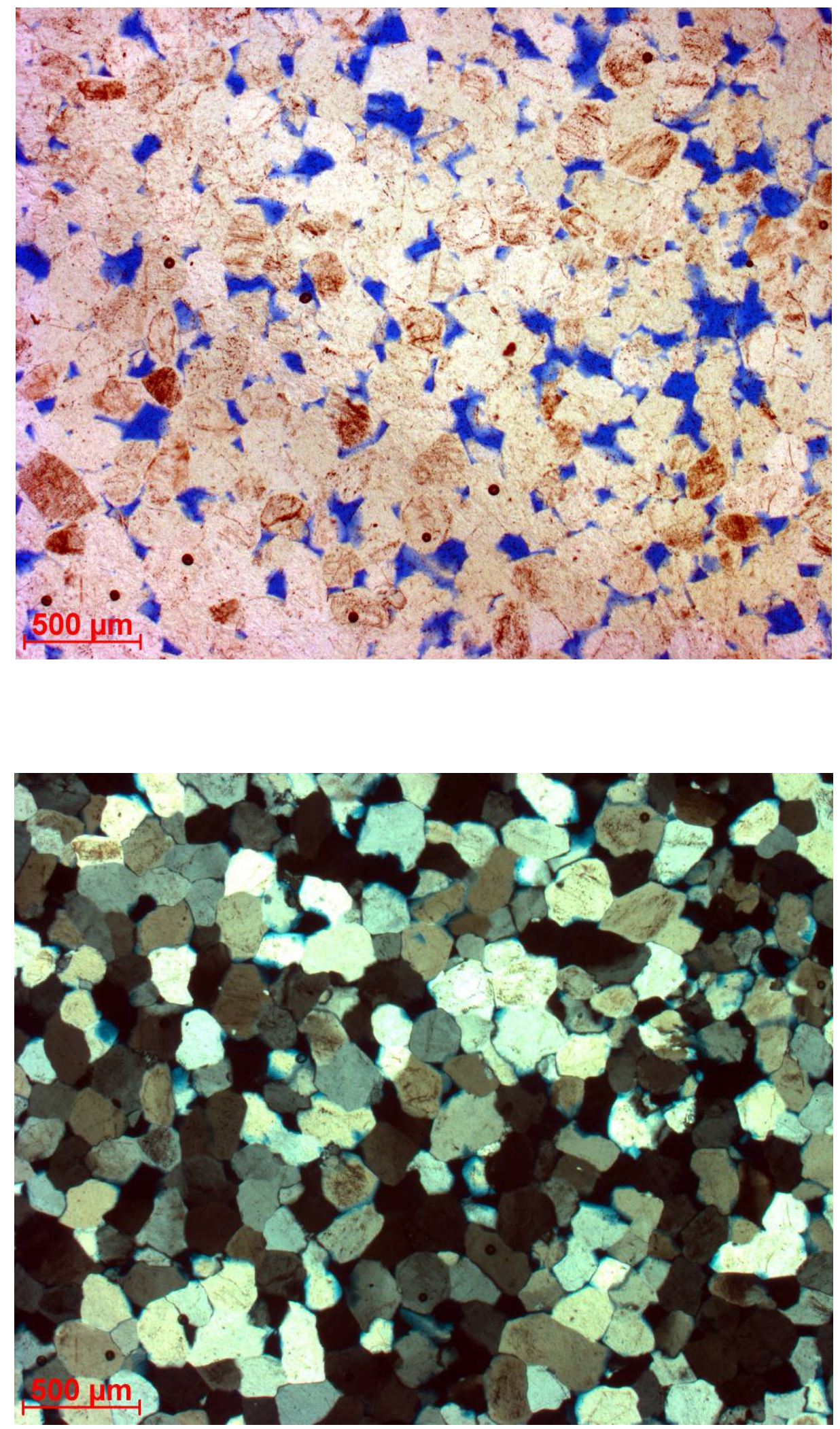
Flechtinger sandstone: plain light (top), crossed nicols (bottom)
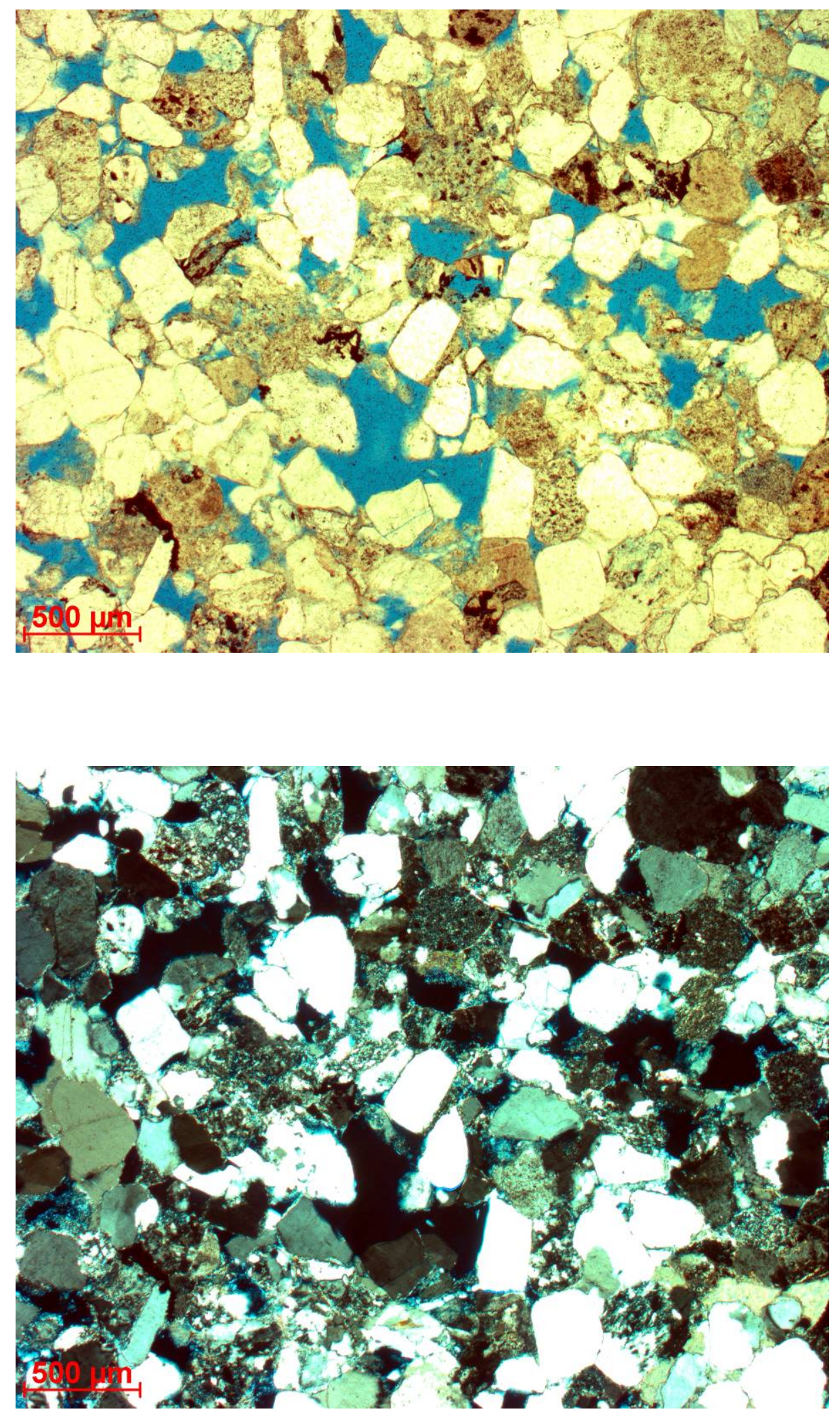
Eberswalder sandstone: plain light (top), crossed nicols (bottom)
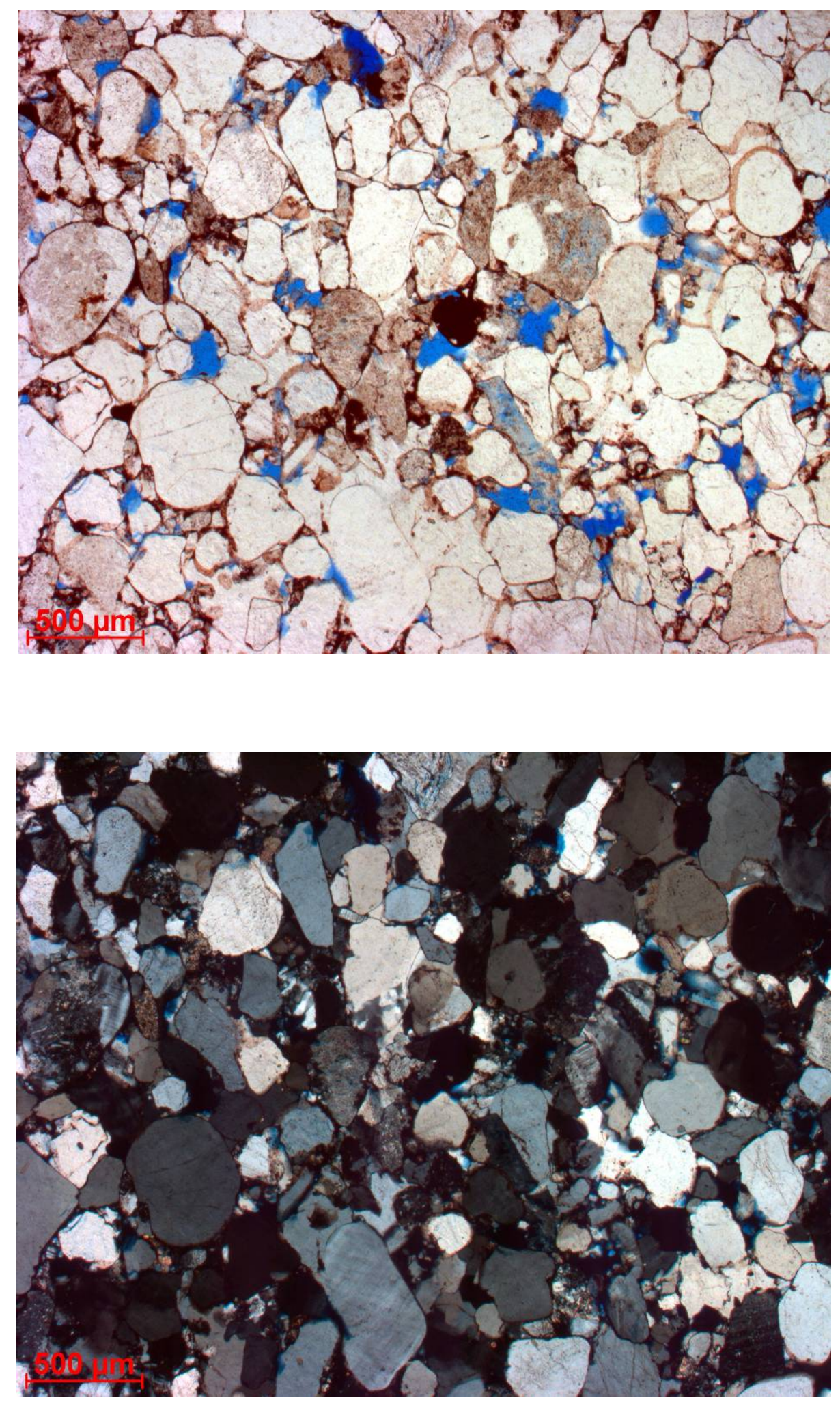


\section{Determination of porosity by thin section micrograph analysis:}

Requirements:

- Microscope (AXIOPLAN, Zeiss)

- high resolution camera (AXIOCAM, Zeiss)

- $\quad$ personal computer and image analysis software (KSrun)

Procedure:

- Adjustment of the thin section micrograph by scaling, smoothening and contrasting

- Segmentation of the pore space by a Hue-Saturation-Brightness Model (Fig. 1)

- Automatic storage of the HSB settings

- Recording of different parts of the thin section with these HSB settings

- From each record a binary image will automatically be generated by HSB filter, erosion and dilatation

- For each pore space various geometrical data will be determined such as area, perimeter length, angle between pore axes, fibre length, etc.

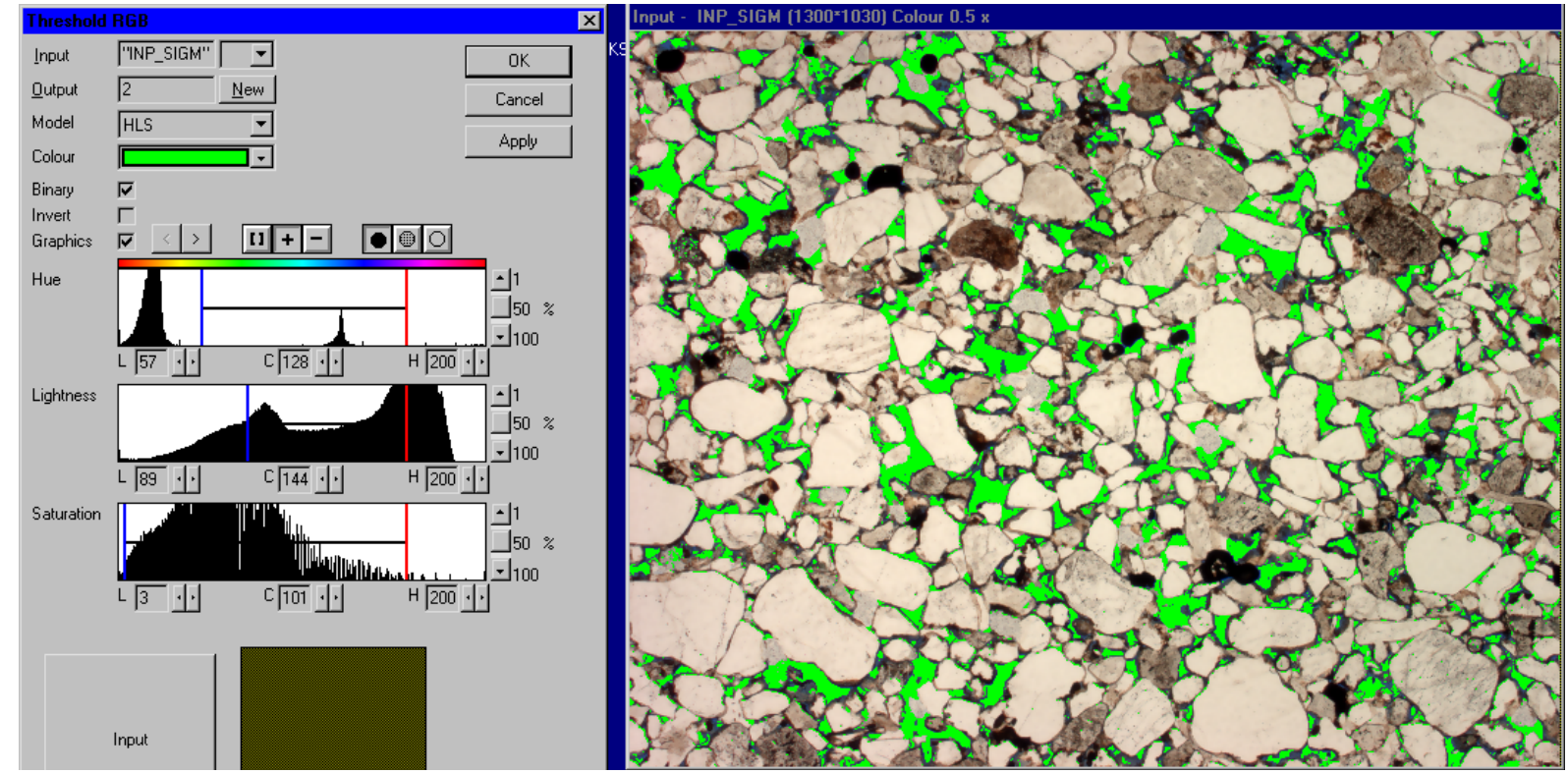

Fig. 1: Segmentation of the pore space: Under the transmitted light microscope the grains appear greyish and the pore space blue (given by the blue epoxy). Therefore, the grains and the pore space differ in hue, saturation and brightness. By adjusting the ranges of HSB the pore space can be visually determined (green). Most differences can be observed for hue and saturation, so the pore space can be well classified.

\section{Error estimation:}

Although the segmentation of the pore space seems an accurate procedure, it also depends on the person in charge. Therefore, the threshold between pore space and grains can vary depending on the user. In order to estimate the related error we changed the threshold manually by erosion and dilatation of the pore space of up to two pixel layers (Fig. 2). The calculated porosities are shown in Diagram 1 for 30 thin section micrographs (Flechtinger sandstone). By reason of the accurate segmentation procedure, the calculated error is a worst case estimate. A true error of less than one pixel layer (erosion and dilatation), resulting in a porosity change of approximately $+/-2 \%$ can be assumed. 


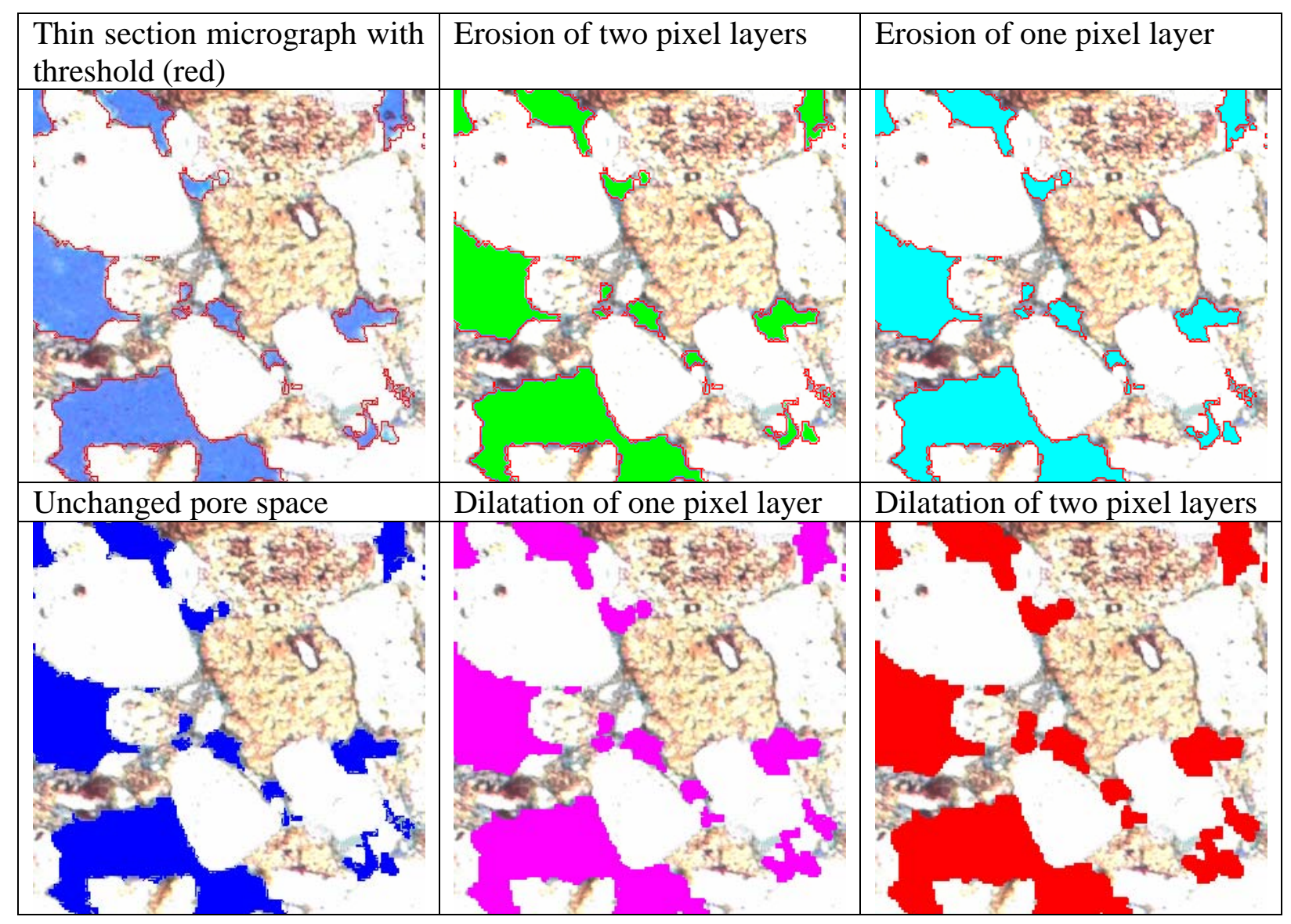

Fig. 2: Estimation of an image analysis error by erosion and dilatation of the pore space.

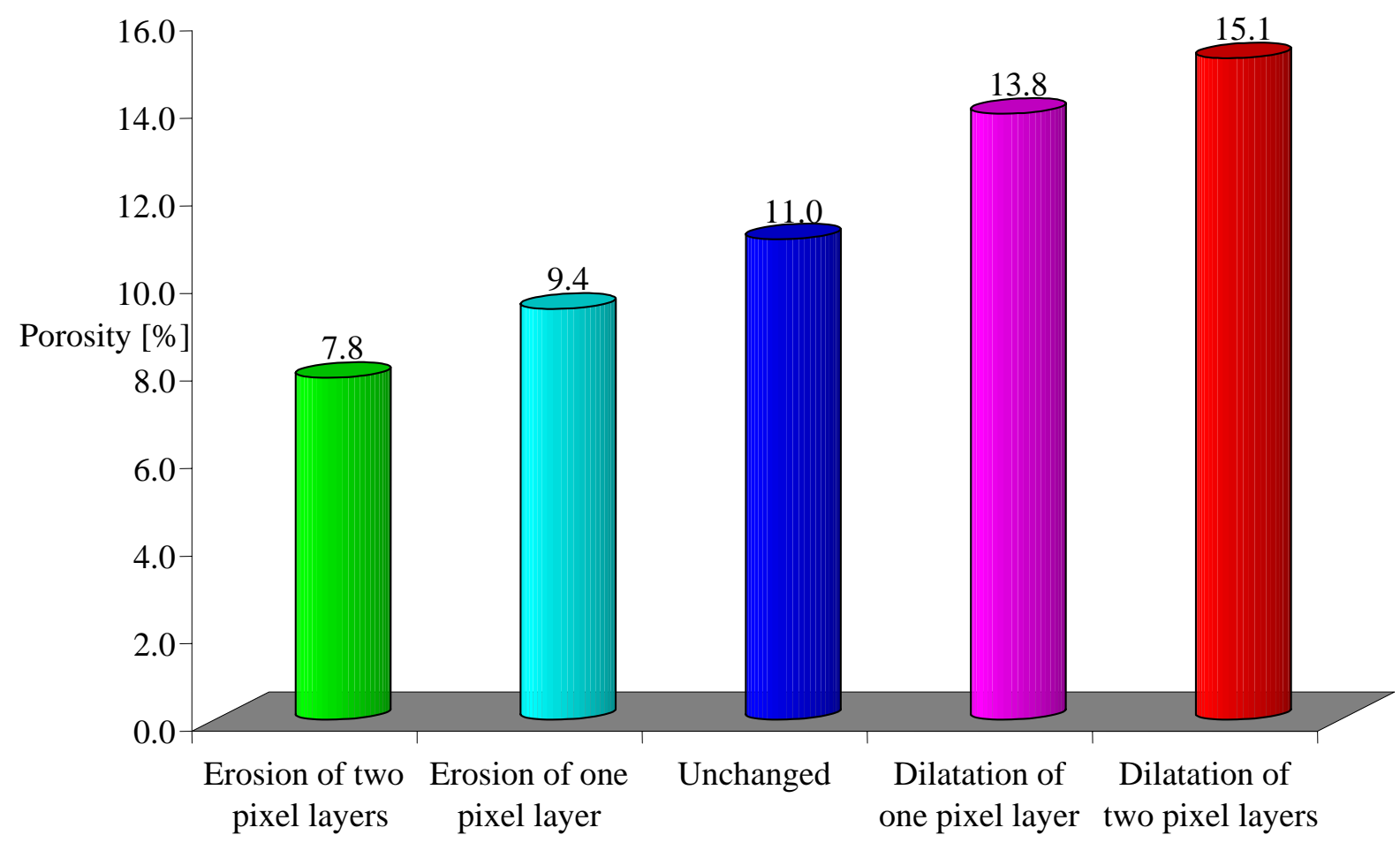

Dia. 1: Calculated porosities for different amounts of erosion and dilatation of the pore space. 


\section{Evaluation of the effect of surface conductivity on the overall sample conductivity:}

Method:

Temperature:

Concentrations:

Conclusion: successive fluid exchange

$40^{\circ} \mathrm{C}$

$0,0.1,0.2,0.3,0.5 \mathrm{~mol} \mathrm{NaCl} / 1 \mathrm{H}_{2} \mathrm{O}$

$+0.4 \mathrm{~mol} \mathrm{NaCl} / 1 \mathrm{H}_{2} \mathrm{O}$ [only Fontainebleau]

$+0.01,0.05 \mathrm{~mol} \mathrm{NaCl} / 1 \mathrm{H}_{2} \mathrm{O}$ [only Flechtinger and Eberswalder]

For all samples, the 0.1 molar $\mathrm{NaCl}$ conductivity data is on a straight line in a $\log [\sigma($ sample $)]-\log [\sigma($ fluid $)]$ plot. This indicates a constant formation factor and thus the predominance of brine- over surface conductivity. The percental ratio $[\sigma($ surface $) / \sigma($ brine; $0.1 \mathrm{~m} \mathrm{NaCl})]$ is approximately 0.1 for the Fontainebleau and the Eberswalder sandstones and 0.5 for the Flechtinger sandstone.

\section{Fontainebleau Sandstone}

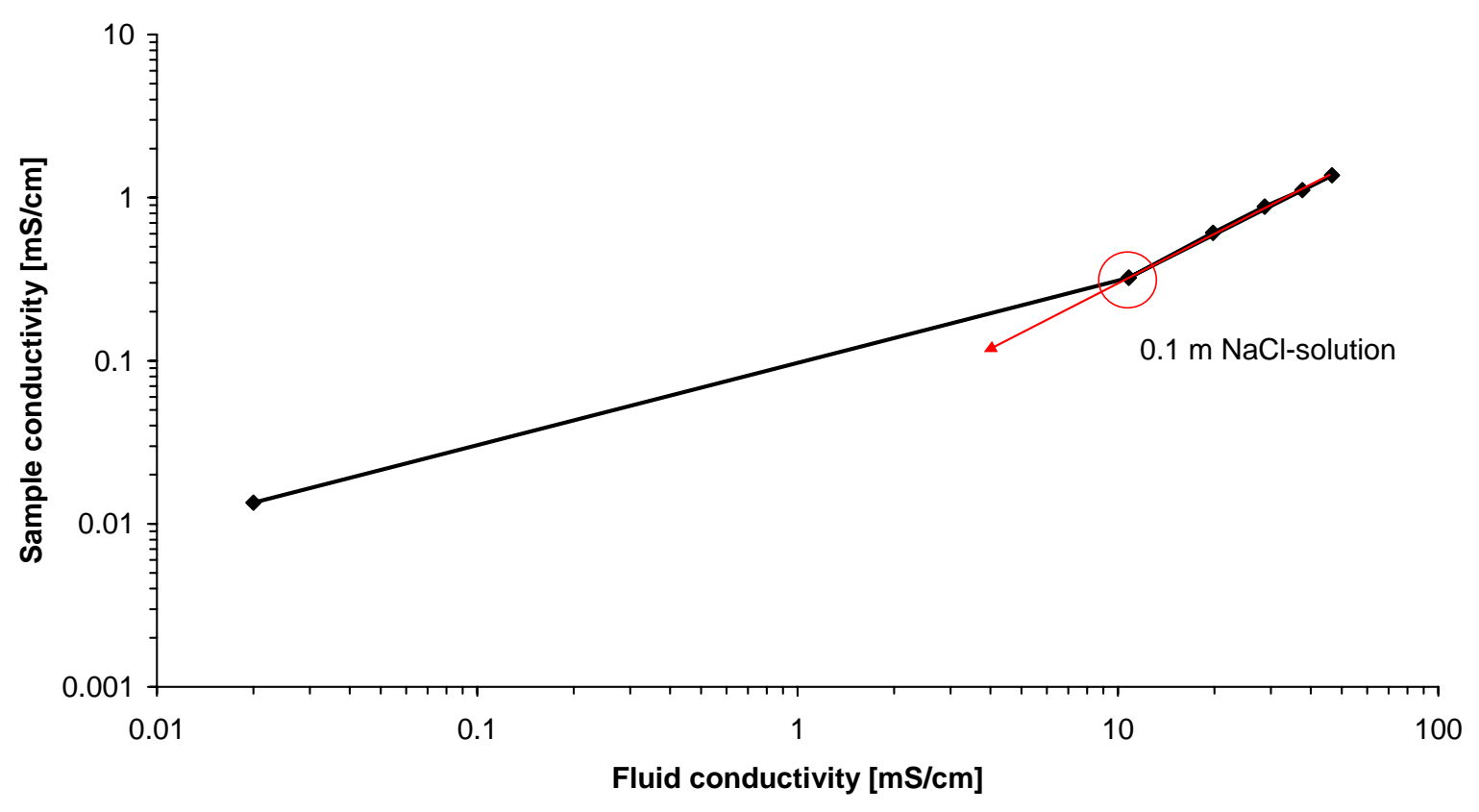


Flechtinger Sandstone

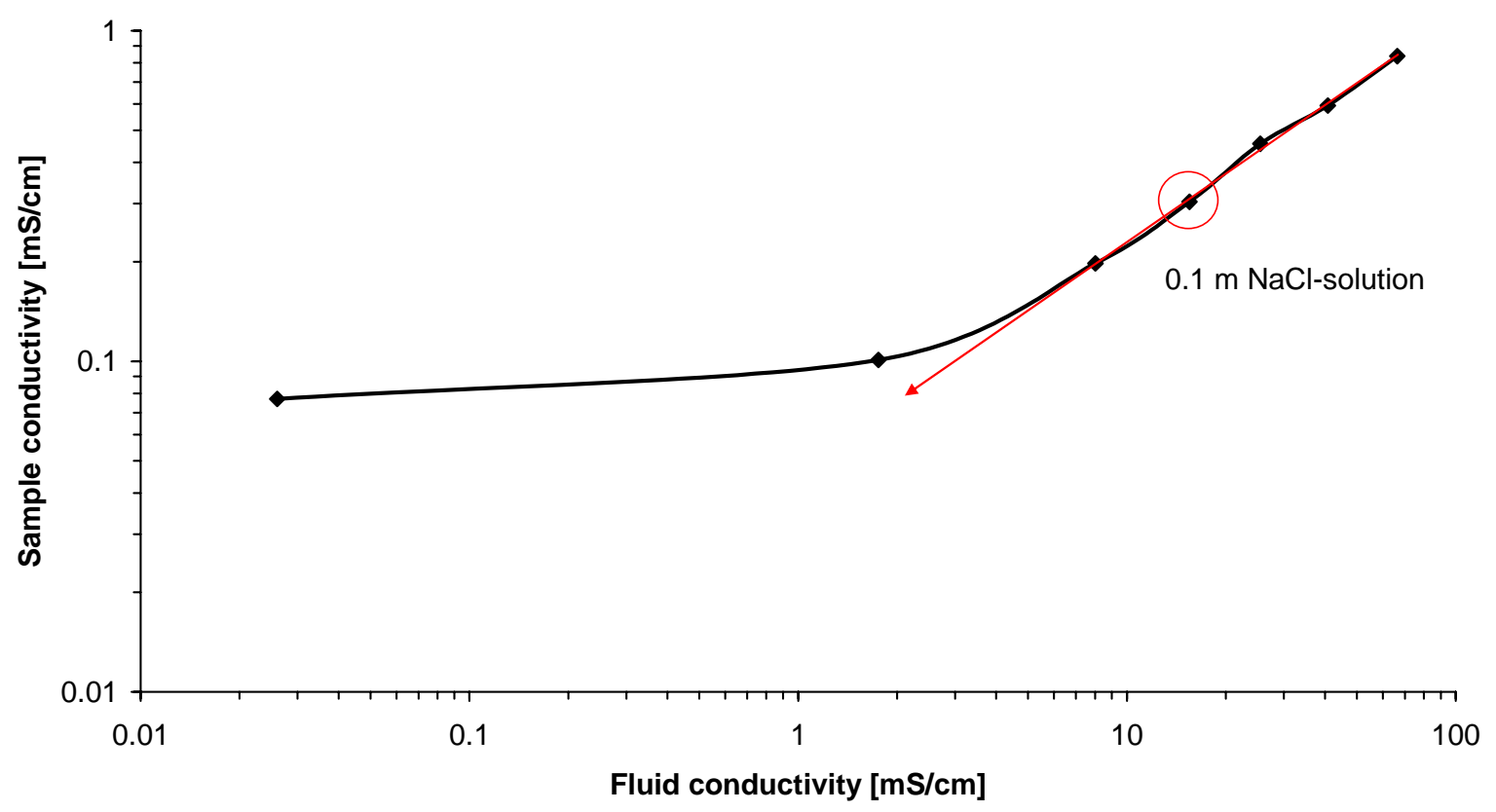

Eberswalder Sandstone

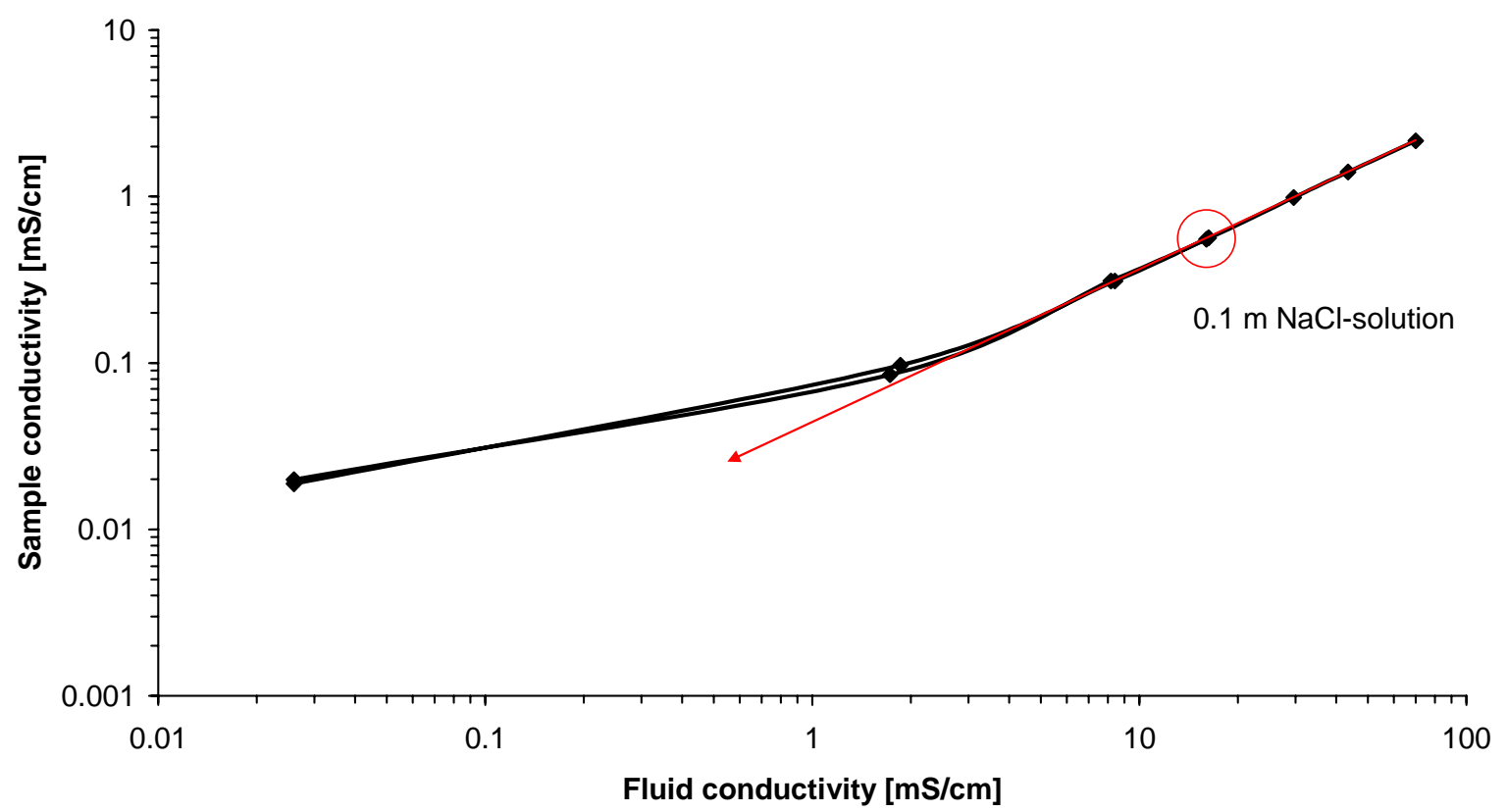


Table 7: Parameters of the empirical permeability-conductivity relationship (Eq. 4).

\begin{tabular}{cccc}
\hline Sample & $r[1]$ & $c L_{E}^{2}\left[10^{-15} \mathrm{~m}^{2}\right]$ & $\begin{array}{c}L_{E}[\mu \mathrm{m}] \text { with } \\
c=1 / 8\end{array}$ \\
\hline Fontainebleau & 1.44 & $21.23 \cdot 10^{3}$ & 13.03 \\
\hline Flechtinger & 1.03 & 1.124 & 0.095 \\
\hline Eberswalder & 2.88 & $1.43 \cdot 10^{3}$ & 3.38 \\
\hline
\end{tabular}

$r$ : empirical constant (Walsh and Brace, 1984);

$c L_{E}^{2}$ : equivalent channel permeability for a formation factor $F=1$; $c$ : arbitrary shape factor;

$L_{E}$ : arbitrary length scale. 